\title{
AfFINITY Profiling AND DisCRIMINATION BY ASSOCIATION IN ONLINE BEHAVIORAL ADVERTISING
}

\author{
Sandra Wachter ${ }^{\dagger}$
}

\begin{abstract}
Affinity profiling - grouping people according to their assumed interests rather than solely their personal traits - has become commonplace in the online advertising industry. Online platform providers use online behavioral advertisement (OBA) and can infer very sensitive information (e.g., ethnicity, gender, sexual orientation, religious beliefs, etc.) about individuals to target or exclude certain groups from products and services, or to offer different prices.

OBA and affinity profiling challenge at least three distinct interests: privacy, nondiscrimination, and group-level protection. This Article first examines several shortfalls of the General Data Protection Regulation (GDPR) concerning governance of sensitive inferences and profiling. It then shows the gaps of E.U. non-discrimination law in relation to affinity profiling in terms of its areas of application as well as the types of attributes and people it protects.

Ultimately, applying the concept of "discrimination by association" can help close some of these gaps in legal protection against OBA. This concept challenges the idea of strictly differentiating between assumed interests and personal traits when profiling people. Discrimination by association occurs when a person is treated significantly worse than others (e.g., not being shown an advertisement) based on their relationship or association (e.g., assumed gender or affinity) with a protected group.

Crucially, the individual does not need to be a member of the protected group to receive protection, which negates the need for people who are part of the protected group to "out" themselves as members of the group (e.g., sexual orientation or religion) to receive protection, if they prefer. Finally, individuals who have been discriminated against but are not actually members of the protected group (e.g., people who have been misclassified as women) could also bring a claim. It would also strengthen the relationship of allies and support of civil rights movements (e.g., LGBTQ+, religious, or women's).

However, the lack of transparent business models could pose a considerable barrier to proving non-discrimination cases. Finally, inferential analytics and AI expand the circle of potential victims by grouping people according to inferred or correlated similarities and characteristics unaccounted for in data protection and non-discrimination law. This Article closes with policy recommendations to address each of these legal challenges.

DOI: https://doi.org/10.15779/Z38JS9H82M

(C) 2020 Sandra Wachter.

† Corresponding author. Sandra Wachter, Associate Professor and Senior Research Fellow, Email: sandra.wachter@oii.ox.ac.uk Oxford Internet Institute, University of Oxford, 1 St. Giles, Oxford, OX1 3JS, UK; the Alan Turing Institute, British Library, 96 Euston Road, London, NW1 2DB, UK. The author would like to thank Dr. Brent Mittelstadt, Dr. Chris Russell, Emmanouil Bougiakiotis, Prof. Philipp Hacker, participants of the Harvard Law Faculty workshop, all participants of the PLSC conference, and, in particular, Frederik Borgesius, Josephine Williams, Ignacio Cofone, Gloria González Fuster, and Gabriela Zanfir-Fortuna for their incredibly helpful and constructive feedback that improved the quality of the paper. Finally, the authors would like to thank the incredible Berkeley Technology Law Journal's editorial team for their fantastic work. This work was supported by the British Academy Postdoctoral Fellowship grant nr PF2 \180114, DeepMind Technologies Limited, The Alan Turing Institute, EPSRC grant EP/N510129/1, the Miami Foundation, and the Luminate Group.
\end{abstract}




\section{TABLE OF CONTENTS}

I. THE TROUBLE WITH AFFINITY PROFILING ........................369

II. AN OVERVIEW OF LEGAL CHALLENGES TO OBA AND AFFINITY PROFILING ....................................................... 375

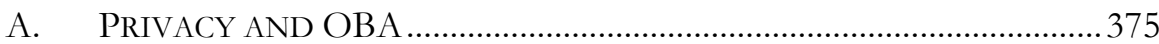

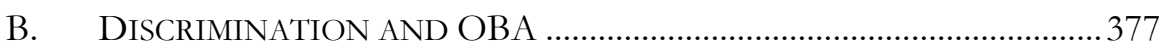

C. AfFinity Profiling, Special Category Data, AND THE GDPR 380

III. E.U. NON-DISCRIMINATION LAW AND AFFINITY PROFILING 385

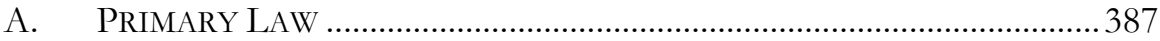

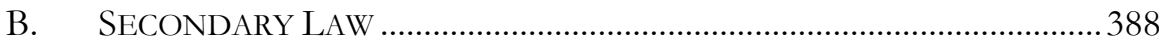

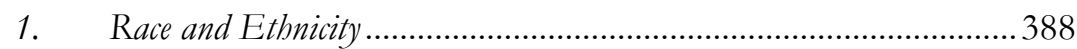

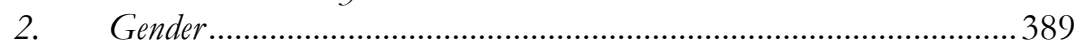

3. Religion or Belief, Disability, Age, or Sexual Orientation...................390

4. $\quad$ Sectoral Divergence in Protected Groups..............................................390

C. CurRent CHALlenges AND Future OPPORTUNities FOR E.U. NON-DISCRIMINATION LAW AND AFFINITY PROFILING..... 392

IV. DISCRIMINATION BY ASSOCIATION AND AFFINITY PROFILING 394

A. Direct Discrimination by Association: The Coleman Case 394

B. INDIRECT DisCRIMINATION BY ASSOCIATION: THE CHEZ CASE .. 398

1. Particular Disadvantage That Is Significantly More Negative in Its Effects on a Protected Group....................................................................... 402

2. Disproportionately Affected in a Negative Way (A Comparator)....... 404

C. JUSTIFICATION OF DISCRIMINATION …............................................... 407

V. PROTECTION OF NON-TRADITIONAL GROUPS................. 413

VI. SOLUTIONS FOR ACCOUNTABILITY IN OBA AND AFFINITY PROFILING ................................................................. 418

A. A Right TO REASONABLE INFERENCES IN OBA ............................ 418

B. CURRENT GOVERNANCE STRATEGIES ............................................. 420

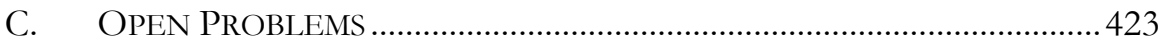

D. POLICY RECOMMENDATIONS............................................................ 427 


\section{THE TROUBLE WITH AFFINITY PROFILING}

Advertisement practices are nothing new; they date back to the late 1950s, when their primary goal—as it is today — was to learn about customers in order to offer them desired products and services. ${ }^{1}$ However, today's advertisements pose new challenges. Digital technologies are now devised to peer even further into the needs, interests, and motivations of customers. Behavioral advertising, online profiling, and behavioral targeting ${ }^{2}$ have become common tactics for suppliers to more effectively ${ }^{3}$ offer products ${ }^{4}$ to customers in the digital environment. ${ }^{5}$

Modern targeted and behavioral advertisements typically involve advertising networks that connect advertisers and publishers (i.e., any entity that wishes to host advertisements such as newspapers) using targeting

1. Ryan Calo, Digital Market Manipulation, 82 GEO. WASH. L. REV. 995, 997 (2013); see generally ROBERT B. CIALDINI, INFLUENCE: THE PSYCHOLOGY OF PERSUASION (2007).

2. For more background on online behavioral advertisement (OBA), see generally Sophie C. Boerman, Sanne Kruikemeier \& Frederik J. Zuiderveen Borgesius, Online Behavioral Advertising: A Literature Review and Research Agenda, 46 J. ADVERT. 363 (2017) (explaining what OBA is and what the privacy concerns are); Edith G. Smit, Guda Van Noort \& Hilde A.M. Voorveld, Understanding Online Behavioural Advertising: User Knowledge, Privacy Concerns and Online Coping Behaviour in Europe, 32 COMPUTERs HuM. BEHAV. 15 (2014) (investigating a study on user knowledge of OBA and cookies, concerns about their privacy, how they cope with OBA, cookies, and the requested informed consent); Steven C. Bennett, Regulating Online Behavioral Advertising, 44 J. MARSHALL L. REV 899 (2011) (examining the regulatory efforts surrounding $\mathrm{OBA}$ and the issues that arise when balancing notions of privacy against the needs of an information-based economy); Aleecia M. McDonald \& Lorrie Faith Cranor, Beliefs and Behaviors: Internet Users' Understanding of Behavioral Advertising, TPRC 2010 (2010), https:// ssrn.com/abstract=1989092 (presenting empirical data on American adult internet users' perceptions and knowledge on internet advertising techniques); Chang Dae Ham \& Michelle R. Nelson, The Role of Persuasion Knowledge, Assessment of Benefit and Harm, and Third-Person Perception in Coping with Online Behavioral Advertising, 62 Comput. Hum. BeHAv. 689 (2016) (discussing a study on OBA and third-party perception).

3. See generally S. C. Matz, M. Kosinski, G. Nave \& D. J. Stillwell, Psychological Targeting as an Effective Approach to digital mass persuasion, 114 PROC. NAT'L ACAD. SCI. 12714 (2017) (analyzing studies that utilized psychological assessment from digital footprints to determine how psychological persuasion influences behavior); JAMES WILLIAMS, STAND OUT OF OUR Light: FreEDom AND RESISTANCE IN THE ATTENTION ECONOMY (2018) (discussing how companies want to capture our attention to sell goods and services).

4. See generally Shoshana Zuboff, Big Other: Surveillance Capitalism and the Prospects of an Information Civilization, 30 J. INFO. TECH. 75 (2015) (describing "surveillance capitalism" and its implications through analysis of Google's practices); SHOSHANA ZubOFF, THE AGE OF Surveillance Capitalism: The Fight for a Human Future at the New Frontier of POWER (2019) (explaining consequences of surveillance capitalism spreading to every economic sector).

5. Calo, supra note 1, at 1002-04; see generally RICHARD H. THALER \& CASS R. SUNSTEIN, Nudge: IMPROVING DECISIONS ABOUT HEALTH, WEALTH, AND HAPPINESS (2009) (discussing the topic of nudging). 
technologies to assemble individual users into target audiences. ${ }^{6}$ In addition to explicit profiles created from data provided by the user, predictive profiles are created by combining user data, background databases, and other information collected by tracking technologies. ${ }^{7}$ Advertisers use these profiles to target groups with-and exclude other groups from-product offers or differentiated prices. Then, as a targeted user browses a publisher's website, advertisers compete via real-time bidding to place their advertisement on that website.

These modern advertising techniques pose three distinct challenges: advertising can (1) potentially violate privacy, (2) unlawfully discriminate against traditionally marginalized groups, and (3) discriminate against and violate the privacy of non-traditional groups who receive inadequate legal protection. Each of these challenges is unpacked in the remainder of this Article; the discussion below provides an overview.

First, the threat to privacy is that "affinity profiling" could sidestep the protections of the E.U. General Data Protection Regulation (GDPR). "Affinity profiling" is profiling which does not directly infer a user's sensitive data ("special category data"), such as personal traits or membership in protected groups, but rather uses other data to measure the user's "affinity" for groups. In other words, affinity profiling looks for a similarity between the assumed interests of a user and the interests of a group. Although Article 9 of the GDPR provides higher protections against processing sensitive personal data (compared to non-sensitive personal data), it may fail to acknowledge a potential relationship between assumed interests and sensitive personal traits. Such a failure would render these higher data protection standards inapplicable to "affinity groups," despite the users' assumed interests having strong and potentially invasive disclosive power. ${ }^{8}$

6. Article 29 Data Protection Working Party, 17/EN WP251REV.01, Guidelines on Automated Individual Decision-Making and Profiling for the Purposes of Regulation 2016/679, (last revised and adopted Feb. 6, 2018) [hereinafter WP Feb. Guidelines]; Frederik J. Zuiderveen Borgesius, Personal Data Processing for Behavioural Targeting: Which Legal Basis?, 5 INT'L DATA PRIV. L. 163, 164 (2015); Chris Jay Hoofnagle, Ashkan Soltani, Nathaniel Good, Dietrich J. Wambach \& Mika D. Ayenson, Behavioral Advertising: The Offer You Can't Refuse, 6 HARV. L \& POL'Y ReV. 273, 275 (2012).

7. WP Feb. Guidelines, supra note 6, at 7.

8. See generally Michal Kosinski, David Stillwell \& Thore Graepel, Private Traits and Attributes Are Predictable from Digital Records of Human Behavior, 110 PROC. NAT'L. ACAD. SCI. 5802 (2013) (describing how Facebook "likes" can reveal intimate information); Christopher Burr, Nello Cristianini \& James Ladyman, An Analysis of the Interaction Between Intelligent Software Agents and Human Users, 28 MiNDS \& MACHINES 735 (2018) (providing an overview on what sensitive information can be disclosed using inferential analytics). 
Moreover, even if the GDPR recognizes that assumed interests reveal sensitive information, this does not automatically equate to higher legal protection for individuals and groups. The General Court of the European Court of Justice (ECJ) ${ }^{9}$ and legal scholars ${ }^{10}$ believe that for these higher protections to apply to inferential analytics, data controllers must both intend to draw sensitive inferences and use source data which provides a reliable basis to learn about sensitive data. If these prerequisites are not met, which may be the case in affinity profiling, the inferences drawn will not be considered special category data or be subject to the stricter protections enshrined in Article 9.

To ensure that sensitive affinity profiling is classified as a type of sensitive data processing within the scope of the GDPR, these artificial thresholds of intent and reliability would need to be abandoned. For platform providers, it is not important to learn sensitive details about one particular user (intent) or to accurately place users into groups or audiences (reliability). As advertising has a high tolerance for classification errors, if a user seems to behave similarly enough to an assumed group (e.g., women), that is sufficient to treat the user as a member of that group (e.g., to show ads for women's shoes).

Second, with regards to E.U. non-discrimination law, the legal status of "affinity groups," or groups based on inferred interests, remains unclear. The key question that courts and scholars will face going forward is: do affinity groups have equivalent legal status to protected groups? For example, would the affinity group "interested in Muslim culture" have equivalent legal status to the group "religion"? The legal status of affinity groups under nondiscrimination law remains unclear. Answering this question is critical: if users are segregated into groups and offered or excluded different products, services, or prices on the basis of affinity, it could raise discrimination issues. ${ }^{11}$ The legal status of affinity groups thus determines which-if any-types of claims can be made under non-discrimination law. Failing to acknowledge the potential

9. See Case T-190/10, Egan v. Parliament, ECLI:EU:T:2012:165, ๆ 84, 101 (Mar. 28, 2012) [hereinafter Egan].

10. See infra Section II.C.

11. On how higher prices are offered to lower income populations, see Jennifer Valentino-DeVries, Jeremy Singer-Vine \& Ashkan Soltani, Websites Vary Prices, Deals Based on Users' Information, WALL ST. J. (Dec. 24, 2012), https://www.wsj.com/articles /SB10001424127887323777204578189391813881534; Jeff Larson, Surya Mattu \& Julia Angwin, Unintended Consequences of Geographic Targeting, TECH. SCI. (Aug. 31, 2015), https:// techscience.org/a/2015090103/ (discussing a study that "found that [ZIP Code Tabulation Areas] with higher percentages of Asian residents were more likely to be quoted one of the higher prices"). 
relationship—be it direct or indirect-between assumed interests and personal traits could render non-discrimination regulation ineffective.

E.U. law recognizes both direct discrimination and indirect discrimination. If affinity groups are granted a legal status equivalent to that of protected groups, individuals would be able to appeal to direct discrimination laws for protection. For direct discrimination to occur, less favorable actions must be explicitly based on protected grounds or attributes (e.g., ethnicity), or a known proxy thereof. To receive relief, a claimant must be part of the protected group (i.e., "direct discrimination"). ${ }^{12}$ Affinity groups could be seen as equivalent to protected groups on the basis that the affinity group (e.g., "interested in Muslim culture") is defined against an explicit protected attribute (e.g., "religion") or a strong proxy for that attribute (e.g., "headscarf wearer"). ${ }^{13}$

If, on the other hand, affinity groups are not granted this equivalent protective legal status, individuals would only be able to appeal to indirect discrimination for protection. Indirect discrimination occurs when different effects for protected groups result from otherwise "apparently neutral provision, criterion or practice ...." In this case, advertisements shown based on assumed affinities would be treated as a type of "neutral provision" because affinity groups are not seen as equivalent to protected groups. To establish discrimination under these conditions, the claimant must prima facie show that the neutral provision could disproportionately affect a protected group when compared with others in a similar situation. In practice, this would mean that the claimant would need to show that a sufficient percentage of the members of the affinity group are likely to be members of a protected group (which would receive disproportionately negative treatment) when compared with others in a similar situation. For instance, this could be achieved by appealing to demographic statistics. To receive relief, the claimant would need to be a member of the disadvantaged protected group.

While remedies are available via direct and indirect discrimination laws, they alone may be insufficient to fully protect affected parties. Thus, the

12. Evelyn Ellis \& Philippa Watson, EU Anti-Discrimination LaW 142-43 (2012).

13. See, e.g., Case C-188/15, Bougnaoui, Association de défense des droits de l'homme (ADDH) v. Micropole SA, ECLI:EU:C:2017:204, ๆๆ 31-32 (Mar. 14, 2017) (leaving open whether the ban of headscarves at the workplace is direct or indirect discrimination).

14. This term is used in all E.U. non-discrimination directives. See, e.g., Council Directive 2000/43/EC, art. 2(2)(b), 2000 O.J. (L 180) 22, 24 (EC) (Racial Equality Directive); Council Directive 2006/54/EC, art. 2(1)(b), 2006 O.J. (L 204) 23, 26 (EU) (Gender Equality Directive (recast)); Council Directive 2004/113/EC, art. 2(b), 2004 O.J. (L 373) 37, 40 (EU) (Gender Access Directive); Council Directive 2000/78/EC, art. 2(2)(b), 2000 O.J. (L 303) 16, 18 (EC) (Employment Directive). 
concepts of direct ${ }^{15}$ and indirect ${ }^{16}$ "discrimination by association" can help increase algorithmic accountability and fairness in OBA.

Applying the concept of "discrimination by association" to OBA is unprecedented, ${ }^{17}$ but would be a powerful tool in the quest for more algorithmic accountability. "Discrimination by association" occurs when a person is treated significantly worse than others (e.g., not being shown an advertisement) based on their relationship or association (e.g., assumed gender or affinity) with a protected group. Protection is granted on the basis of an individual's association with a group defined by legally protected attributes (or an accepted proxy) which have led to differential treatment or results (e.g., being shown advertisements for lower paying jobs).

This could have implications for OBA for three main reasons. First, it would overcome the argument that inferring one's "affinity for" and "membership in" a protected group are strictly unrelated. If an interest group is seen as equivalent to a protected group, it does not matter whether the measure taken is based on a protected attribute that an individual possesses or because they are somehow associated with the protected group (e.g., having an interest in a specific culture). In such a case, claims under direct discrimination by association are possible. Second, both direct and indirect discrimination require the claimant to be a member of the protected group in order to receive relief. As a result, to invoke either type of claim under non-discrimination law, affected parties may need to "out" themselves (e.g., in relation to sexual orientation or religion). This could be a problem, as there might be reasons an individual may not wish to disclose potentially sensitive personal attributes. Discrimination by association negates the need for people who are part of the protected group to "out" themselves as members of the group in order to receive protection. Finally, because claimants do not need to be members of the protected group to receive protection, individuals who have received discriminatory treatment but are not actually members of the protected group (e.g., people who have been misclassified as women) could also bring a claim. Both wrongly and accurately classified people who suffered adverse treatment because of their assumed affinity and interests can claim relief via discrimination by association. Widening the circle of potential claimants could

15. See, e.g., Case C-303/06, Coleman v. Law, 2008 E.C.R. I-415 [hereinafter Coleman] (providing an example of direct discrimination).

16. See, e.g., Case C-83/14, CHEZ Razpredelenie Bulgaria AD v. Komisia za zashtita ot diskriminatsi, ECLI:EU:C:2015:480 (July 16, 2015) [hereinafter CHEZ] (providing an example of indirect discrimination).

17. The notion of direct and indirect discrimination by association was established in Coleman, supra note 15, and CHEZ, supra note 16. 
also have the positive side effect of strengthening the relationship of allies of civil rights movements (e.g., LGBTQ+, religious, women's). Moreover, not granting protection to misclassified users could have an undesirable chilling effect due to fear over potential negative consequences based on associating with these groups.

Most interestingly, an ECJ judgment shows that certain seemingly neutral actions can also constitute direct discrimination (by association).$^{18}$ If affinity profiling is seen as direct discrimination, almost no legal justification will be available to publishers or advertisers. ${ }^{19}$ Even if affinity profiling is only seen as indirect discrimination, economic and business concerns alone are unlikely to justify differential results. ${ }^{20}$ However, practical challenges remain, such as the lack of algorithmic transparency and opaque business models, that will make it difficult for affected parties to demonstrate prima facie discrimination.

Finally, the third challenge that OBA poses is to non-traditional groups. Even with the most generous interpretation of data protection and nondiscrimination law, profiling and inferential analytics disrupt fundamental tenets of data protection and non-discrimination law, and may render them inapplicable. The scope of data protection law may fall short because profiling can occur without identifying an individual and often without using any personal data. ${ }^{21}$ And the scope of non-discrimination law may fall short because constructed groups do not necessarily map onto legally protected characteristics based on historical lessons. ${ }^{22}$ Both legal frameworks must be revised to account for the privacy of "ad hoc groups" to overcome these shortcomings. ${ }^{23}$

This Article examines in detail the three challenges that OBA and affinity profiling pose in terms of privacy protection, non-discrimination, and group privacy. It proceeds as follows. Part II explores the regulation around the collection and legitimate uses of sensitive data and inferences. This Part reveals current limitations and loopholes in the GDPR. Part III examines E.U. nondiscrimination law and sheds light on the lack of comprehensiveness in the types of decision-making and people it protects. Part IV focuses on direct and indirect discrimination by association and explores its potential to close current accountability gaps in relation to OBA and affinity profiling. Part V discusses

18. CHEZ, supra note 16, at $9129(3)$.

19. ELLis \& WATSON, supra note 12, at 173.

20. See infra Section IV.C.

21. Sandra Wachter, Data Protection in the Age of Big Data, 2 Nature Elec. 6, 7 (2019).

22. See Alessandro Mantelero, AI and Big Data: A Blueprint for a Human Rights, Social and Ethical Impact Assessment, 34 COMPUT. L. \& SEC. REV. 754, 765 (2018).

23. Brent Mittelstadt, From Individual to Group Privacy in Big Data Analytics, 30 PHIL. \& TECH. 475, 476, 485 (2017). 
the concept of group privacy and the "right to reasonable inferences" as necessary tools to close existing gaps in privacy and non-discrimination protection. Finally, Part VI discusses current governance strategies and closes with a set of recommendations on what kind of transparency tools should be offered to users to increase algorithmic transparency and accountability in $\mathrm{OBA}^{24}$

\section{AN OVERVIEW OF LEGAL CHALLENGES TO OBA AND AFFINITY PROFILING}

OBA and affinity profiling face several significant legal challenges in Europe across privacy, data protection, and non-discrimination law.

\section{A. PRIVACY AND OBA}

The most evident concern with OBA is its potential to violate individual privacy. ${ }^{25}$ Internet technologies can be used to track users across the web over time and gather information about their surfing behavior and interests. ${ }^{26}$ This information is then used to build profiles which can be very invasive, often revealing users' explicit and subconscious interests, personality traits, and behaviors. ${ }^{27}$ Among other things, tailored advertising can be based on those profiles. $^{28}$ To tailor advertising to specific users, ad networks use cookies ${ }^{29}$ that record information about the users and remember if they return to specific

24. It is worth noting that this Article does not examine consumer protection law, such as Directive 2006/114/EC concerning misleading and comparative advertising and Directive 2005/29/EC concerning unfair commercial practices. While potentially relevant, these frameworks go beyond the scope of this Article.

25. See Bennett, supra note 2, at 904-06; see also Tal Z. Zarsky, Privacy and Manipulation in the Digital Age, 20 Theoretical InQuires L. 157, 158 (2019).

26. See, e.g., Bin Bi, Milad Shokouhi, Michal Kosinski \& Thore Graepel, Inferring the Demographics of Search Users: Social Data Meets Search Queries, in Proc. 22ND INT'L CONF. ON World Wide Web 131 (2013); Alvaro Ortigosa, Rosa M. Carro \& José Ignacio Quiroga, Predicting User Personality by Mining Social Interactions in Facebook, 80 J. COMPUT. SYS. SCI. 57 (2014); Zijian Wang, Scott A. Hale, David Adelani, Przemyslaw A. Grabowicz, Timo Hartman, Fabian Flöck \& David Jurgens, Demographic Inference and Representative Population Estimates from Multilingual Social Media Data, in WorLD Wide WeB CoNF. 2056 (2019).

27. See generally Matz et al., supra note 3.

28. See Omer Tene \& Jules Polenetsky, To Track or "Do Not Track": Advancing Transparency and Individual Control in Online Behavioral Advertising, 13 MINN. J.L. SCI. \& TECH. 281, 282-83 (2012); WP Feb. Guidelines, supra note 6, at 7.

29. Andrew McStay, I Consent: An Analysis of the Cookie Directive and Its Implications for UK Behavioral Advertising, 15 NEw MEDIA \& SOC'Y 596, 597-98 (2013). For more on the numerous different tracking cookies, see Jonathan R. Mayer \& John C. Mitchell, Third-Party Web Tracking: Policy and Technology, 2012 IEEE SYMP. ON SECURITY \& PRIVACY 413, 420-21 (2012). 
websites or visit partner sites. ${ }^{30}$ Sites sometimes also add additional information, such as zip code, age, or gender, based on user activity such as search queries. Each piece of information helps the ad network to serve appropriate ads for the user. ${ }^{31}$ Sophie C. Boerman et al. ${ }^{32}$ provide an overview of the methods (e.g., flash cookies and device fingerprints ${ }^{33}$ ) as well as characteristics and data tracked in behavioral advertising. According to them, profiles are built from various types of data such as clicking and page-reading behavior, geolocation, videos watched, and search queries, ${ }^{34}$ as well as app-use data, purchases, posts on social media, and emails. ${ }^{35}$

The constant collection and evaluation of personal data enables companies to gain very intimate insights into the lives of their customers. Using sensitive tags to target users has become common practice. ${ }^{36}$ Many scholars have long been aware of these issues, ${ }^{37}$ with some believing that advertisers will continue to increasingly rely on personalized and targeted advertising in the future. ${ }^{38}$ Potentially sensitive information such as religious or political beliefs, sexual

30. WP Feb. Guidelines, supra note 6, at 6.

31. Bennett, supra note 2, at 900.

32. Boerman et al., supra note 2, at 364 (finding evidence of widespread use of inferential analytics).

33. See Ibrahim Altaweel, Nathaniel Good \& Chris Jay Hoofnagle, Web Privacy Census, TECH. SCI. (2015), https://techscience.org/a/2015121502/.

34. For an overview of existing methods of OBA, see Boerman et al., supra note 2 , at 364.

35. See Frederik J. Zuiderveen Borgesius, Improving Privacy Protection in the Area of Behavioural Targeting (manuscript at 1) (Sept. 1, 2015), https://papers.ssrn.com/sol3 /papers.cfm?abstract_id $=2654213$.

36. Juan Miguel Carrascosa, Jakub Mikians, Ruben Cuevas, Vijay Erramilli \& Nikolaos Laoutaris, I Always Feel like Somebody's Watching Me: Measuring Online Behavioural Advertising, in Proc. 11Th ACM Conf. On Emerging Networking Experiments \& Tech. 1, 1-2 (2015).

37. See, e.g., VikTor Mayer-Schönberger \& Thomas Ramge, Reinventing Capitalism in the Age of Big Data (2018); Tene \& Polenetsky, supra note 28; Bennett, supra note 2; Frederik J. Zuiderveen Borgesius, Singling Out People Without Knowing Their NamesBehavioural Targeting, Pseudonymous Data, and the New Data Protection Regulation, 32 ComPUT. L. \& SEC. Rev. 256 (2016); Calo, supra note 1; VikTOR MAYER-SchÖnberger \& KenNeth Cukier, Big Data : A Revolution that Will Transform How We Live, Work And THINK (2013); Tal Z. Zarsky, Mine Your Own Business: Making the Case for the Implications of the Data Mining of Personal Information in the Forum of Public Opinion, 5 YALE J.L. \& TECH. 1 (2002); Danielle Keats Citron \& Frank Pasquale, The Scored Society: Due Process for Automated Predictions, 89 Wash. L. Rev. 1 (2014); Frank Pasquale, The Black Box Society: The Secret Algorithms that CONTROL MONEY AND Information (2015).

38. See, e.g., Boerman et al., supra note 2, at 363; V. Kumar \& Shaphali Gupta, Conceptualizing the Evolution and Future of Advertising, 45 J. ADVERT. 302, 303 (2016); Don Schultz, The Future of Advertising or Whatever We're Going to Call It, 45 J. ADVERT. 276, 283-84 (2016); Roland T. Rust, Comment: Is Advertising a Zombie?, 45 J. ADvERT. 346, 346-47 (2016). 
orientation, race or ethnicity, physical or mental health status, or sex or gender identity can be inferred from online behavior without users ever being aware. ${ }^{39}$ For example, researchers suggested that Facebook can infer sexual orientation (and other sensitive characteristics) based on a user's interactions with the platform. ${ }^{40}$

\section{B. DISCRIMINATION AND OBA}

Discrimination is also a common concern with OBA among scholars. According to Ariel Ezrachi and Maurice E. Stucke, from an economic perspective, the "rise of behavioural discrimination" and price discrimination can limit the autonomy of consumers in choosing products and their power on the free market. ${ }^{41}$ However, privacy, personalization, and price discrimination are not the only concerns with OBA. A landmark study by Latanya Sweeney revealed how OBA can reinforce racial stereotypes, stigmatize users, and possibly illegally discriminate. ${ }^{42}$ Her study showed that names associated with Black people prompted more ads by "instantcheckmate.com"-indicating an arrest-than was the case for names associated with White people. ${ }^{43}$ The causal root of this finding is not selfevident; it may be rooted in the methods advertisers use to market their product (e.g., search criteria, ad text, and bids), or it may reflect the clicking behavior of users. The optimization of OBA algorithms towards higher clickthrough rates can inadvertently reinforce stereotypes. ${ }^{44}$

Unfortunately, this is not the only example of discriminatory OBA. In general, research suggests that algorithms can be inadvertently biased favoring men over women for STEM jobs on platforms such as Facebook, Google, Instagram, and Twitter. ${ }^{45}$ This trend cannot be attributed entirely to algorithmic reinforcement of stereotypes. ProPublica published a series of

39. See Sandra Wachter \& Brent Mittelstadt, A Right to Reasonable Inferences: Re-Thinking Data Protection Law in the Age of Big Data and AI, 2 Colum. Bus. L. Rev. 494, 506-10 (2019).

40. José González Cabañas, Ángel Cuevas \& Rubén Cuevas, Facebook Use of Sensitive Data for Advertising in Europe (Feb. 14, 2018) (unpublished manuscript), https:// arxiv.org/pdf/1802.05030.pdf. For a discussion of the revealing power of Facebook "likes," see Kosinski, Stillwell \& Graepel, supra note 8, at 5802-04.

41. Ariel Ezrachi \& Maurice E. Stucke, The Rise of Behavioural Discrimination, EuR. Competition L. ReV. 485, 485-90 (2016); see also Frederik Zuiderveen Borgesius \& Joost Poort, Online Price Discrimination and EU Data Privacy Law, 40 J. CONSUMER POL'Y 347 (2017).

42. See Latanya Sweeney, Discrimination in Online Ad Delivery, 11 ACM Queue 10, 19 (2013).

43. Id. at 4.

44. Id. at $14-15$.

45. L. Elisa Celis, Anay Mehrotra \& Nisheeth K. Vishnoi, Toward Controlling Discrimination in Online Ad Auctions (May 22, 2019) (unpublished manuscript), https:// arxiv.org/pdf/1901.10450.pdf. 
reports showing that Facebook allows advertisers to exclude certain groups (e.g., from housing, employment, and credit offers), based on ethnicity ${ }^{46}$ or gender. ${ }^{47}$ Facebook has also used the "likes" of users to infer sexual orientation and has allowed advertisers to serve young LGBTQ+ users "gay cure" advertisements. ${ }^{48}$ Only recently has Facebook announced a change to their policy: when placing ads in relation to housing, jobs, or credit, advertisers can no longer use classes such as race, ethnicity, sexual orientation, and religion as general targeting options. ${ }^{49}$

However, Facebook still allows advertisers to create custom audiences based on personally identifiable information (PII), for instance by matching visitors of pages with Facebook users via Pixel. ${ }^{50}$ Custom audiences can be used by advertisers to target people based on gender, location, age, language, "lookalike audiences," ${ }^{51}$ source audiences ${ }^{52}$ (e.g., fans of a Facebook page), and

46. Terry Parris Jr., Julia Angwin \& Madeleine Varner, Facebook Lets Advertisers Exclude Users by Race, PROPUBLICA (Oct. 28, 2016), https://www.propublica.org/article/facebook -lets-advertisers-exclude-users-by-race; Ariana Tobin \& Julia Angwin, Facebook (Still) Letting Housing Advertisers Exclude Users by Race, ProPublicA (Nov. 21, 2017), https:// www.propublica.org/article/facebook-advertising-discrimination-housing-race-sex-national -origin; Ariana Tobin \& Jeremy B. Merrill, Facebook Moves to Block Ad Transparency ToolsIncluding Ours, ProPubliCA (Jan. 28, 2019), https://www.propublica.org/article/facebook -blocks-ad-transparency-tools.

47. Jeremy B. Merrill \& Ariana Tobin, Facebook Is Letting Job Advertisers Target Only Men, ProPublica (Sept. 18, 2018), https://www.propublica.org/article/facebook-is-letting-job -advertisers-target-only-men.

48. Helena Horton \& James Cook, Facebook. Accused of Targeting Young LGBT Users with “Gay Cure” Adverts, Telegraph (Aug. 25, 2018), https://www.telegraph.co.uk/news/2018 /08/25/facebook-accused-targeting-young-lgbt-users-gay-cure-adverts/.

49. Sheryl Sandberg, Doing More to Protect Against Discrimination in Housing, Employment and Credit Advertising, FACEBOOK NEWSROOM, https://about.fb.com/news/2019/03/protecting -against-discrimination-in-ads/ (last visited Mar 24, 2019). A promise to change this policy was made in the past as well. See Ariana Tobin, Facebook Promises to Bar Advertisers From Targeting Ads by Race or Ethnicity. Again., ProPuBlica (2018), https://www.propublica.org/article / facebook-promises-to-bar-advertisers-from-targeting-ads-by-race-or-ethnicity-again.

50. About Reaching New Audiences, FACEBOOK FOR BusINESS, https:// www.facebook.com/business/help/717368264947302?id=176276233019487 (last visited April 20, 2020).

51. About Lookalike Audiences, FACEBOOK FOR BUSINESS, https://www.facebook.com /business/help/164749007013531?id=401668390442328 (last visited Mar 24, 2019) ("A Lookalike Audience is a way to reach new people who are likely to be interested in your business because they're similar to your best existing customers.”). For more on the privacy risks of this method, see generally Giridhari Venkatadri, Athanasios Andreou, Yabing Liu, Alan Mislove, Drishna P. Gummadi, Patrick Loiseau \& Oana Goga, Privacy Risks with Facebook's PII-Based Targeting: Auditing a Data Broker's Advertising Interface, 2018 IEEE SYMP. ON SEC. \& PRIV. 89 (2018).

52. Source Audience, FACEBOOK FOR BUSINESS, https://en-gb.facebook.com/business /help/475669712534537 (last visited Mar 24, 2019). 
detailed targeting. ${ }^{53}$ Detailed targeting allows advertisers to target or exclude people based on preferences, intents, or behaviors (e.g., travel, time spent on a network, education, pages they engage with, relationship status, income, children, or political affiliation) for users in certain locations. ${ }^{54}$ Till Speicher et al. thus suggest that the concerns raised above remain because proxy data can be used in lieu of explicit sensitive characteristics and platform data can be linked to public (e.g., voter registration) and private datasets (e.g., via data brokers) to gain intimate insights about users. ${ }^{55}$ According to Speicher et al., similar approaches seem to be taken by platforms such as Twitter, Pinterest, LinkedIn, and YouTube. ${ }^{56}$

These examples demonstrate that affinity profiling and detecting bias are more than a technological challenge. It is also a societal challenge ${ }^{57}$ made possible by implicit and explicit biases ${ }^{58}$ and stereotypical thinking. They reveal

53. About Detailed Targeting, FACEBOOK FOR BusINESS, https://www.facebook.com /business/help/182371508761821?id=176276233019487 (last visited May 11, 2019).

54. See Mary Lister, All of Facebook's Ad Targeting Options in 1 Epic Infographic, WordSTREAM BLOG (Feb. 26, 2020) https://www.wordstream.com/blog/ws/2016/06/27 / facebook-ad-targeting-options-infographic (last visited Mar 24, 2019). Some of these options are available only in the United States.

55. See Till Speicher, Muhammad Ali, Giridhari Venkatadri, Filipe Nunes Ribeiro, George Arvanitakis, Fabrício Benevenuto, Drishna P. Gummadi, Patrick Loiseau \& Alan Mislove, Potential for Discrimination in Online Targeted Advertising Till Speicher MPI-SWS MPI-SWS MPI-SWS, in 81 Proc. Conf. on Fairness, Accountability, \& Transparency 1, 5 (2018).

56. Id. at 2 .

57. See generally Cathy O’Neil, Weapons of Math Destruction: How Big Data InCREASES INEQUALity AND Threatens Democracy (2017); Virginia Eubanks, Automating Inequality: How High-Tech Tools Profile, Police, and Punish the Poor (2018); SAfiya Umoja Noble, Algorithms of Oppression: How SEArCh Engines REINFORCE RACISM (2018).

58. See generally Matt Kusner, Joshua Loftus, Chris Russell \& Ricardo Silva, Counterfactual Fairness, in Proc. $31^{\text {st }}$ CONF. ON NEURAL Info. Processing SYs. 4069 (2017) (discussing the challenges of detecting bias in data sets); Chris Russell, Matt J. Kusner, Joshua R. Loftus \& Ricardo Silva, When Worlds Collide: Integrating Different Counterfactual Assumptions in Fairness, in Proc. 31st Conf. on Neural Info. Processing Sys. 6396 (2017); Cynthia Dwork, Moritz Hardt, Toniann Pitassi, Omer Reingold \& Richard Zemel, Fairness Through Awareness (Nov. 30, 2011) (unpublished manuscript), https://arxiv.org/pdf/1104.3913.pdf; Sorelle A. Friedler, Carlos Scheidegger \& Suresh Venkatasubramanian, On the (Im)Possibility of Fairness (Sept. 23, 2016) (unpublished manuscript), https://arxiv.org/pdf/1609.07236.pdf; Nina GrgićHlača, Muhammad Bilal Zafar, Krishna P. Gummadi \& Adrian Weller, The Case for Process Fairness in Learning: Feature Selection for Fair Decision Making, in NIPS SYMP. ON MACHINE LEARNING \& L. (2016); Celis, Mehrotra \& Vishnoi, supra note 45; Speicher et al., supra note 55. 
that discriminatory behavior can be profitable, which can incentivize companies to allow advertisers to exclude specific groups. ${ }^{59}$

\section{AfFinity Profiling, Special CATEgory Data, AND the GDPR}

When first confronted with the issues of affinity profiling, Facebook explained that they do not infer ethnicity directly, but rather only infer affinity with a specific culture based on a user's interaction with the platform (e.g., likes, friends, and groups). ${ }^{60}$ How does this argument fit within the context of European data protection law?

Under Article 9 of the GDPR, the processing of sensitive data is only allowed under certain circumstances. Article 9 provides an exclusive list of data types that necessitate higher levels of protection, including ethnic origin, political opinions, religious or philosophical beliefs, trade union membership, and data concerning a natural person's sex life or sexual orientation. ${ }^{61}$

This list does not cover all known types of data that can cause stigma and discrimination. For example, sex and gender are not included in the list. The Article 29 Working Party discussed this lack of comprehensiveness in an advice paper and suggested expanding the definition of sensitive data in future regulation to at least include information about financial status, minors, geolocation, and profiles. ${ }^{62}$ This is a sensible approach because financial status and geolocation are known to be strong proxies for gender or sex and ethnicity. It is noteworthy, however, that the Working Party did not propose to include gender or sex as a type of sensitive data, even though this type of data can cause discrimination. ${ }^{63}$ In the end, the Working Party's proposal was not adopted in the GDPR. This is a worrying result as all these types of data can be the root of unfair or unjust treatment.

59. See Muhammad Ali, Piotr Sapiezynski, Miranda Bogen, Aleksandra Korolova, Alan Mislove \& Aaron Rieke, Discrimination Through Optimization: How Facebook's Ad Delivery Can Lead to Skewed Outcomes, in 3 Proc. ACM on Hum.-COMPut. InTERACTION 1, 1 (2019).

60. Alex Hern, Facebook's "Ethnic Affinity" Advertising Sparks Concerns of Racial Profiling, GUARDIAN (Mar. 22, 2016), https://www.theguardian.com/technology/2016/mar/22 / facebooks-ethnic-affinity-advertising-concerns-racial-profiling.

61. Regulation (EU) 2016/679 of the European Parliament and of the Council of 27 April 2016 on the protection of natural persons with regard to the processing of personal data and on the free movement of such data, and repealing Directive 95/46/EC (General Data Protection Regulation), 2016 O.J. (L 119) 1 [hereinafter GDPR].

62. Article 29 Data Prot. Working Party, Advice Paper on Special Categories of Data ("Sensitive Data"), at 10, Ares(2011)444105 - 20/04/2011 (2011), https://perma.cc/Q6PY -9KAP (last visited Oct 1, 2017) [hereinafter Art. 29 WP Advice Paper].

63. For an extensive discussion on several laws failing to guard against sensitive inferences, see generally Wachter \& Mittelstadt, supra note 39. 
Following the advice paper of the Article 29 Working Party ("Working Party") on the definition of personal data and the phrasing in Article 9 of the GDPR (specifically the usage of the word "revealing" in the definition), ${ }^{64}$ it is safe to assume that "special category data" covers both sensitive data and data that can be sensitive by inference. In other words, "special category data" is not limited to data that directly reveals sensitive information such as "religion," but also includes data from which sensitive information can be concluded (e.g., a picture showing a person wearing religious attire). ${ }^{65}$

With regards to inference, academics disagree on the requirements for personal data to be classified as sensitive data. ${ }^{66}$ For some, the intent to infer sensitive attributes is required (an intention requirement). For example, if a pizzeria delivers food to customers in a drug abuse center, their addresses are not considered sensitive data because the pizzeria is presumably not interested in inferring their health status. ${ }^{67}$ Similarly, it has been suggested that if sensitive data is only captured coincidentally it should not be classified as sensitive, unless the type of data is known to contain sensitive content. Following this reasoning, it has been argued that images captured by CCTV camera of visitors of "gay meeting spots" would not be considered sensitive data unless the purpose of the camera was to record "gay meeting spots." 68 'The same has been argued for camera footage capturing people wearing religious attire. ${ }^{69}$ However, the Working Party has argued that camera footage is inherently problematic because it can reveal ethnic origin or health status. ${ }^{70}$

In addition to the intention requirement, some scholars argue that there is a second requirement: the data collected must provide a reliable basis to infer

64. See Art. 29 WP Advice Paper, supra note 62, at 6 ("The term 'data revealing racial or ethnic origin, political opinions, religious or philosophical beliefs, trade-union membership' is to be understood that not only data which by its nature contains sensitive information is covered by this provision, but also data from which sensitive information with regard to an individual can be concluded.").

65. See Alexander Nguyen, Videoüberwachung insensitiven Bereichen, 35 DATENSCHUTZ DATENSICHERHEIT 715, 715 (2011) (discussing CCTV and pictures allowing sensitive inferences).

66. For an overview on this academic debate, see Wachter \& Mittelstadt, supra note 39, at $560-68$.

67. Sebastian Schulz, Art. 9 Verarbeitung besonderer Kategorien personenbezogener Daten, in DatenschutZ-GrundVERORDnUng VO (EU) 2016/679 295 xi-xiv (Peter Gola ed., 1st ed. 2017).

68. Nguyen, supra note 65, at 517.

69. Schulz, supra note 67 , at xii-xiii.

70. Art. 29 WP Advice Paper, supra note 62, at 8 (stating that a particular data type can be problematic in terms of revealing sensitive attributes without regard to the intent or purpose of the controller collecting the data, thereby logically suggesting that intention may be irrelevant to the classification of personal data as sensitive data). 
sensitive attributes. For example, pornographic browsing history is seen as sufficient to infer sexual orientation, geolocation of cell phones at political events can be used to infer political beliefs, and names, country of birth, and addresses provide a reliable basis to infer ethnicity or religious beliefs. ${ }^{71}$ Some scholars also argue that reliability does not need to be unambiguously proven for the classification to apply; it is sufficient that a data controller can realistically make these assumptions, taking into account the purpose of data collection (i.e., intent). ${ }^{72}$ In contrast, other scholars deny that the aforementioned data types have sufficient sensitive disclosive power to qualify as special category data. ${ }^{73}$

The General Court has previously affirmed that reliability is a necessary precondition to transform personal data into sensitive data. In Egan $v$. Parliament, the complainants requested access to the names of the personal assistants of a member of the European Parliament. ${ }^{74}$ The personal assistants did not want this information to be disclosed, arguing that their working relationship could be used to infer their political stances. The court ruled that an employment relationship is not sufficiently reliable to draw inferences about political beliefs. ${ }^{75}$

What does this mean for affinity profiling? In order for Article 9 of the GDPR to apply, sensitive data or data that is sensitive by inference has to be collected or processed. The argument that higher protection standards should not apply if the data is used to infer an affinity with an ethnicity, rather than ethnicity directly, is problematic because it too narrowly interprets the scope

71. AleXANDer SCHIFF, DS-GVO Art. 9 Besonderer Kategorien personenbezogener Daten, in DatenschutZ-GrundVERORDnUng 334 xxvi-xxvii (Eugen Ehmann \& Martin Selmayr eds., 1st ed. 2017).

72. Id. at $\mathrm{xx}-\mathrm{xxii}$.

73. Schulz, supra note 67 , at xii-xiii.

74. Egan, supra note 9, at 101.

75. The Court explains:

Furthermore, in response to the applicants' argument that data concerning former MEP assistants were previously accessible, the Parliament argued, in its defence, that it cannot release such data, as they would reveal the assistants' political opinions and would therefore be sensitive data within the meaning of Article 10 of Regulation No 45/2001 .... However, that argument, which, moreover, is not in any way substantiated, cannot, in any event, make up for the fact that the contested decision failed to show why disclosure of those data would specifically and effectively undermine their right to privacy within the meaning of Article 4(1)(b) of Regulation No $1049 / 2001$.

Id. (internal citations omitted). 
of "special category data." " Such data has great inferential power because personal interests allow inferences to be drawn about personal traits. In other words, an interest in something sensitive (e.g., LGBTQ+ rights) is different than collecting sensitive data about a user (e.g., sexual orientation). Failing to acknowledge the power of sensitive disclosures about a person's life made possible by assuming their interests will render the higher protection in the GDPR inapplicable, meaning only the normal standards for personal data would apply.

However, even if this disclosive power is acknowledged, intent and reliability are problematic thresholds when applied to targeted advertising and, especially, affinity profiling. The main reason is that sensitive attributes do not need to be intentionally inferred to have an influence on advertisements. For example, as mentioned above, Facebook explained that they have no intention to infer sensitive traits, but only to assume an affinity. ${ }^{77}$ Despite this lack of intent, Facebook was accused of inferring very intimate details about their users by proxy (e.g., ethnicity, sexual orientation, and political views) ${ }^{78}$ If proxy data (e.g., assumed interests) can reveal sensitive traits without any intent to do so, it shows that this artificial threshold to turn personal data into sensitive data is misguided. If this view is continued, companies could learn sensitive information about users without necessarily being bound to the higher safeguards and standards in the GDPR that normally accompany such data. In effect, they could be able to advertise to users based on sensitive characteristics, or an affinity with such characteristics, without incurring the higher legal safeguards in Article 9 that such advertising would normally incur.

The requirement of reliability for the GDPR to protect this type of data is also a red herring and very problematic for advertisements. The question is not only whether sensitive information can be reliably inferred, but also how these inferences change the way advertisers and platform providers treat their users. It is also problematic that sexual orientation, for instance, is inferred, be it

76. GDPR, supra note 61, at 38 (art. 9). Special category data is defined as "personal data revealing racial or ethnic origin, political opinions, religious or philosophical beliefs, or trade union membership, and the processing of genetic data, biometric data for the purpose of uniquely identifying a natural person, data concerning health or data concerning a natural person's sex life or sexual orientation ...." Id. The phrase "personal data revealing" shows that the definition is not intended to only capture explicit usage of protected attributes, but rather data that when processed can reveal information about one of the listed categories. See $i d$. Data revealing an affinity with an ethnicity should thus be considered special category data.

77. Hern, supra note 60.

78. Parris Jr. et al., supra note 46; Horton \& Cook, supra note 48; Alex Hern, Facebook Lets Advertisers Target Users Based on Sensitive Interests, GUARDIAN (May 16, 2018), https:// www.theguardian.com/technology/2018/may/16/facebook-lets-advertisers-target-users -based-on-sensitive-interests. 
directly or by affinity, but the harm may continue after the inference is drawn. Platform providers tailor content (e.g., ads, news feeds, and search results) based on these assumptions (e.g., based on assumed gender). Platforms do not necessarily care whether they accurately place users into certain groups; rather, what matters is whether the user behaves similarly enough to the assumed group to be treated as a member of the group. The opportunity cost of showing ads intended for women to men that have been misclassified is very low. The business model of OBA can tolerate relatively high rates of misclassification. This tolerance does not, however, benefit misclassified users who are offered inaccurate or discriminatory content and may suffer as a result. The focus on reliability is therefore misguided. People will be treated differently based on their assumed affinity, regardless of whether this assumption is correct.

If the reliability requirements advanced by the General Court and some scholars are upheld, it could render Article 9 inapplicable to affinity profiling and leave the data with only the normal standards of data protection. This is problematic given that affinity profiling (which does not require an intention to infer sensitive data) could cause the same privacy harms as direct collection and inference of sensitive data.

The Working Party offers a more generous definition in their guidelines on sensitive data. ${ }^{79}$ This definition is operationalized in their guidelines on OBA, where they argue, "if an ad network provider processes individual behavior in order to 'place him/her' in an interest category indicating a particular sexual preference they would be processing 'sensitive data.' "80 According to the European Data Protection Board's guidelines on the targeting of social media users, this holds true regardless of whether the inferences are accurate (e.g., if the person is actually politically right or left wing) ${ }^{81}$ This view aligns with the European Data Protection Board's opinion on inferred political views. ${ }^{82}$ Unfortunately, the European Data Protection Board seems to insist on the intent requirement, and so personal data only

79. Art. 29 WP Advice Paper, supra note 62, at 6.

80. Artitcle 29 Data Protection Working Party, Opinion 2/2010 on online behavioural advertising, 00909/10/EN WP 17120 (2010), https://ec.europa.eu/justice /article-29/documentation/opinion-recommendation/files/2010/wp171_en.pdf (last visited Mar. 22, 2019) [hereinafter "Art. 29 Data Prot. Working Party, Opinion 2/2010"].

81. Eur. Data Prot. Board, Guidelines 8/2020 on the targeting of social media users 30 (2020), https://edpb.europa.eu/sites/edpb/files/consultation/edpb_guidelines_202008_onthetarge tingofsocialmediausers_en.pdf.

82. Eur. Data Prot. Board, Statement 2/2019 on the Use of Personal Data in the Course of Political Campaigns 1 (2019), https://edpb.europa.eu/sites/edpb/files/files/file1/edpb-2019 -03-13-statement-on-elections_en.pdf. 
turns into sensitive data if the data controller has the intent to do so. This is a problem as algorithms will infer sensitive details regardless of intent. ${ }^{83}$

This view leads to higher data protection standards around the usage of special category data. Article 9 only permits a limited range of cases for using such data. One of these cases is explicit consent, which is a higher bar than informed consent as described in Article 7. Legitimate interests (Article 6(2)(f)) or the necessity to fulfill a contract (Article 6(1)(b)) cannot be used to collect special category data. ${ }^{84}$ Following this, the Working Party has explained in their OBA guidelines that data controllers will need to seek explicit consent to collect sensitive data and that "in no case would an opt-out consent mechanism meet the requirement of the law." $" 85$

These processing requirements, arbitrary thresholds, and conflicting views of the General Court and the Working Party leave affinity profiling in a legal grey area. If the argument holds that affinity profiling does not predict or infer sensitive information about the data subject, but only assumes an interest with a protected group, data controllers might not need to comply with Article 9. Only standard legal bases for processing personal data (either opt-in consent via Article 7 of the GDPR or an objection to processing via Article 21 GDPR) could apply to affinity profiling. Even if affinity profiling is classified as a type of sensitive data processing, the intentionality and reliability thresholds to turn personal data into sensitive data might prevent the higher protections of Article 9 from applying, even though the privacy harms of sensitive data and assumed affinity can be the same.

\section{E.U. NON-DISCRIMINATION LAW AND AFFINITY PROFILING}

As the previous Section showed, Article 9 of the GDPR could prove ineffective at protecting against privacy invasive inferential analytics. Privacy is not, however, the only concern with affinity profiling. Concerns with discrimination might also arise if only certain groups are shown an ad (possibly even with different product prices) or excluded from the audience, and these groups share protected characteristics (e.g., gender, sexual orientation, or religious beliefs). This Section will first shed light on the scope and limits of E.U. non-discrimination law and then demonstrate how the concept of

83. Art. 29 Data Prot. Working Party, Opinion 2/2010, supra note 80, at 31.

84. Of course, Article 9 offers other legitimate bases to collect special category data, such as employment, vital interests of the data subject, or research. These, however, are less likely to form a legitimate basis for advertisement. In other words, if advertisers want to use special category data, it is very likely that explicit consent will be the only legitimate grounds.

85. Art. 29 Data Prot. Working Party, Opinion 2/2010, supra note 80, at 20. 
discrimination by association could be used to close some of the current loopholes in the law to offer greater protection against affinity profiling.

E.U. non-discrimination law has its roots in both primary ${ }^{86}$ and secondary law. ${ }^{87}$ These two regulations have different scopes, have different ways of enforcement, and apply to different actors. ${ }^{88}$ Primary and secondary nondiscrimination law prohibits two types of discrimination: direct and indirect discrimination.

Direct discrimination means that an individual or group is treated less favorably in comparison to others in a similar situation, and the treatment is based on a protected ground (e.g., ethnicity) without any justification rooted in the law. ${ }^{89}$ In the context of OBA, direct discrimination is rarer than indirect discrimination because an advertiser or platform provider is not likely to confess that a protected ground formed the basis for a decision.

Indirect discrimination refers to a seemingly "neutral provision, criterion or practice" $"$ (e.g., the decision to show certain ads to people based on their assumed interests) that affects protected groups in a significantly more negative way than others in a comparable situation, and thus results in differential results. ${ }^{91}$ Indirect discrimination can be legally justified when a legitimate aim is pursued and the means to achieve it are necessary and proportionate. ${ }^{92}$ Statistics can play a significant role in establishing legitimacy because the claimant must provide evidence to prove that differential effects occurred (more on that below).

86. ElLis \& WATSON, supra note 12, at 13. For a fantastic overview of the scope, history, and effectiveness of E.U. non-discrimination law, see generally SANDRA FREDMAN, Discrimination LAW (2011); MARK BELl, ANTi-Discrimination LAW AND THE EUROPEAN UNION (2002).

87. ELLIS \& WATSON, supra note 12, at 19-21.

88. Id. at 20. Primary law refers to the "founding" treaties of the European Union (including the E.U. Charter of Fundamental Rights), whereas secondary law refers to all legislative acts that are derived from these treaties such as regulations, directives, decisions, opinions, and recommendations. EU Law, EUROPEAN JUSTICE, https://e-justice.europa.eu /content_eu_law-3--maximize-en.do (last updated Mar. 1, 2019).

89. See ElLis \& WATSON, supra note 12, at 142.

90. This is stated in all E.U. Non-Discrimination Directives. See, e.g., Council Directive 2000/43/EC, supra note 14, at art. 2(2)(b); see also Christopher McCrudden, The New Architecture of EU Equality Law After CHEZ: Did the Court of Justice Reconceptualise Direct and Indirect Discrimination?, EUR. EQUAL. L. REV. 1, 3 (2016).

91. ELLIS \& WATSON, supra note 12, at 143.

92. This is stated in the E.U. non-discrimination directives. 
To the benefit of claimants, only prima facie discrimination must be demonstrated to bring a direct or indirect discrimination case. ${ }^{93}$ Once prima facie discrimination is successfully raised, the burden of proof shifts to the alleged offender to refute it. ${ }^{94}$

To prove prima facie direct discrimination, an identifiable victim does not need to be found because the potential harm need not actually occur. ${ }^{95}$ In other words, it is not necessary that the discriminatory practice (e.g., only showing job ads to men) result in negative effects (e.g., less women applying for a job). The burden of proof shifts if "the causation between the protected ground and the harm is only probable or likely." 96

Finally, in both cases of discrimination, intent does not need to be proven. ${ }^{97}$ Even good-faith and well-intentioned practices can amount to discrimination if the adverse result of the treatment disproportionately affects members of protected groups in comparison with others in a similar situation..$^{98}$ Even with the best intentions, platform providers can commit direct or indirect discrimination.

\section{A. PRIMARY LAW}

The widest scope of non-discrimination exists in the primary law of the European Union. Article 21 of the E.U. Charter of Fundamental Rights ("the Charter") states that "[a]ny discrimination based on any ground such as sex, race, colour, ethnic or social origin, genetic features, language, religion or belief, political or any other opinion, membership of a national minority, property, birth, disability, age or sexual orientation shall be prohibited." ${ }^{\prime 9}$ This

93. Lilla Farkas \& DeClain O’Dempsey, How to Present a Discrimination Claim: HANDBOOK ON SEEkING REMEDIES UNDER THE EU NON-DiscriminAtion DiRECTIVES 52 (2011).

94. On prima facie discrimination and shifting the burden of proof, see Sandra Fredman, The Reason Why: Unravelling Indirect Discrimination, 45 IND. L. J. 231, 235 (2016). On shifting burden of proof, see, for example, Council Directive 2006/54/EC, supra note 14, art. 19 (gender discrimination cases); Council Directive 2000/78/EC, supra note 14, art. 10 (employment discrimination cases); Council Directive 2000/43/EC, supra note 14, art. 8 (race discrimination cases); see also Council Directive 97/80/EC, 1997 O.J. (L 14) 6 (EC).

95. For an example involving racist job ads, see Case C-54/07, Centrum voor gelijkheid van kansen en voor racismebestrijding v. Firma Feryn NV, 2008 E.C.R. I-397, ๆ 25.

96. Lilla Farkas \& Orlagh O'Farrell, European Commission, REVERSing the Burden of Proof: Practical Dilemmas at the European and National Level 47 (2015).

97. ELLIS \& WATSON, supra note 12, at 167.

98. Eur. Union AgENCY FOR Fundamental Rights \& COUNCIL OF EuR., HANDBOOK ON EUROPEAN NON-DisCRIMINATION LAW 239-42 (2018).

99. Charter of Fundamental Rights of the European Union, art. 21, 2007 O.J. (C 303) 1, 7. 
is a non-exclusive list that is sector-neutral. However, these provisions only apply to E.U. institutions and institutions of the Member States if they implement European Law. ${ }^{100}$ Thus, only public bodies of the European Union and public bodies of the Member States in matters of E.U. law are bound by these provisions. ${ }^{101}$

\section{B. SECONDARY LAW}

In contrast, secondary law applies to both private and public sectors. Compared with primary law, the protections defined in secondary law are limited both in terms of the types of people protected (exclusive list protecting from discrimination based on race and ethnicity, gender, religion and belief, age, disability, and sexual orientation) and the sectors covered (only employment, the welfare system, and access to goods and services, including housing are covered).$^{102}$ However, the directives must be in accordance with the Charter.

\section{Race and Ethnicity}

The most far-reaching protection in secondary law can be found in the Racial Equality Directive. ${ }^{103}$ Article 3 of the Racial Equality Directive prohibits discrimination based on race or ethnicity in the context of employment, access to the welfare system, social protection, education, as well as goods and services. With regards to OBA, these protections extend to unjustified discrimination based on ethnicity-be it directly or indirectly-in advertisements offering jobs or (ads for) goods and services (e.g., products,

100. However, the ECJ has opened the possibility of letting the principle of nondiscrimination in the Charter apply to private entities as well. See generally Case C-144/04, Werner Mangold v. Rüdiger Helm, 2005 E.C.R. I-9981; Case C-414/16, Vera Egenberger v. Evangelisches Werk für Diakonie und Entwicklung eV, ECLI:EU:C:2018:257 (Apr. 17, 2018); Case C-555/07, Seda Kücükdeveci v Swedex GmbH \& Co. KG., 2010 E.C.R. I-365.

101. See Charter of Fundamental Rights of the European Union, art. 51, 2000 O.J. (C 364) $1,21$.

102. See Ellis \& Watson, supra note 12, at 22-42; Fredman, Discrimination LAW, supra note 86 , at $109-53$.

103. Council Directive 2000/43/EC, supra note 14. 
loans, insurance, or housing). ${ }^{104}$ Such discriminatory advertisements are illegal, unless legally justified. ${ }^{105}$

\section{Gender}

Equality between men and women is guaranteed in two directives: the Gender Equality Directive (recast) ${ }^{106}$ and the Gender Access Directive. ${ }^{107}$ Both frameworks cover less ground than the Racial Equality Directive. ${ }^{108}$ The Gender Equality Directive guarantees equality in employment. However, equal treatment is only guaranteed for social security and not in the broader welfare system, including social protection and access to healthcare and education. ${ }^{109}$ In most cases, showing or not showing job ads based on gender is illegal (because the ads are within the realm of employment, a protected sector), unless legally justified.

The Gender Access Directive, as opposed to the Racial Equality Directive, excludes media content, advertisements, and education from its scope. ${ }^{110}$

104. Similarly, E.U. consumer protection law requires that ethnicity or country of residence within the European Union cannot be used as a basis for price discrimination. See European Union, Pricing, payments and price discrimination in the EU, YOUR EUROPE - CITIZENS, https://europa.eu/youreurope/citizens/consumers/shopping/pricing-payments/index _en.htm (last visited Apr 20, 2020). Further, the proposed Digital Services Act promises stricter regulation on digital commerce. See Madhumita Murgia \& Mehreen Khan, EU draws up sweeping rules to curb illegal online content, FinANCIAL TIMES (July 24, 2019), https:// www.ft.com/content/e9aa1ed4-ad35-11e9-8030-530adfa879c2.

105. See infra Section III.C.

106. Council Directive 2006/54/EC, supra note 14; see also Case C-13/94, P v S and Cornwall County Council 1996 E.C.R. I-02143 (protecting transsexual people against gender and sex discrimination if they seek to undergo gender reassignment surgery).

107. Council Directive 2004/113/EC, 2004 O.J. (L 373) 37 (EU) (Gender Access Directive).

108. On the hierarchy of protected groups and the political reasons, see Dagmar Schiek, Broadening the Scope and the Norms of EU Gender Equality Law: Towards a Multidimensional Conception of Equality Law, 12 MAASTRICHT J. EUR. \& COMP. L. 427, 438 (2005).

109. Eur. UNiOn AgENCY FOR Fundamental Rights \& COUNCIL OF EuR., supra note 98 , at 22 .

110. Council Directive 2004/113/EC, supra note. 107, at 40 (art. 3(3)). Other legitimate aims that limit the scope of the Directive are:

[d]ifferences in treatment may be accepted only if they are justified by a legitimate aim. A legitimate aim may, for example, be the protection of victims of sex-related violence (in cases such as the establishment of single sex shelters), reasons of privacy and decency (in cases such as the provision of accommodation by a person in a part of that person's home), the promotion of gender equality or of the interests of men or women (for example single-sex voluntary bodies), the freedom of association (in cases of membership of single-sex private clubs), and the organisation of sporting activities (for example single-sex sports events). 
Originally it was planned to cover a vast range of sensitive areas such as social assistance, education, media, advertising, and taxation, but these sectors were ultimately not included. ${ }^{111}$ Samantha Besson argues that, in general, the Court of Justice of the European Union's (CJEU) case law applies a higher level of scrutiny on nationality and age than gender. ${ }^{112}$

\section{Religion or Belief, Disability, Age, or Sexual Orientation}

As demonstrated in Sections III.B.1-2, compared to other protected classes, E.U. law offers the least protection against discrimination based on religion or beliefs, disability, age, and sexual orientation. These attributes are only protected in the context of employment, ${ }^{113}$ but not in relation to the welfare system or with respect to the purchase of goods and services. As it currently stands, E.U. law allows advertisements offering goods and services (including housing, financial services, and insurance) to discriminate based on these traits.

Since 2008, the so-called Horizon Directive has been under discussion in order to partially remedy this gap in non-discrimination law in the European Union. ${ }^{114}$ The Horizon Directive aims to implement "the principle of equal treatment between persons irrespective of religion or belief, disability, age or sexual orientation" beyond the realm of employment. ${ }^{115}$ Despite the debate lasting over eleven years, the Horizon Directive remains in draft form, and the current draft does not address the gaps in non-discrimination law based on sex or gender. ${ }^{116}$

\section{Sectoral Divergence in Protected Groups}

Depending on the context in which ads are served, different groups will be protected. Ads in the context of employment must adhere to the safeguards against discrimination in relation to employment. Other types of ads will

Id. at 38 .

111. Eur. Parliamentary Research Serv., Gender Equal Access to Goods and SERVices Directive 2004/113/EC: EuRopeAn IMPLEMENTATION ASSESSMENT I-7 (2017); Schiek, supra note 108, at 429-30 (criticizing the limited scope of the Directive due to lobbying efforts of the insurance industry).

112. Samantha Besson, Gender Discrimination Under EU and ECHR Law: Never Shall the Twain Meet?, 8 Hum. RigHTS L. REV. 647, 665-67 (2008).

113. Council Directive 2000/78/EC, supra note 14.

114. See generally Proposal for a Council Directive on Implementing the Principle of Equal Treatment between Persons Irrespective of Religion or Belief, Disability, Age or Sexual Orientation, COM (2008) 426 final (July 2, 2008) (Horizon Directive).

115. Id. at 2.

116. See id. For an overview of the regulatory history of anti-discrimination law and the Horizon Directive, see generally Mark Bell, Advancing EU Anti-Discrimination Law: The European Commission's 2008 Proposal for a New Directive, 3 EQUAL RigHTS REV. 7 (2009). 
generally fall within the realm of protection of equal access to goods and services.

Employment advertisements must adhere to the highest legal standards because E.U. law offers protection to the broadest set of groups, specifically those defined by ethnicity, gender, religion or belief, disability, age, or sexual orientation. Given that companies ${ }^{117}$ have been accused of favoring men or even excluding women from seeing job ads despite such practices likely being illegal under the Gender Equality Directive, this topic is of critical concern. ${ }^{118}$

When offering goods and services, the Directives do not allow gender and ethnicity to be used to restrict access. In contrast, religion or belief, disability, age, or sexual orientation can be used in this regard. However, the Gender Access Directive allows gender (but not ethnicity) to be used as a factor to discriminate in relation to media, advertising, and education content. It is indeed problematic that media and advertising are excluded from the scope because they can be the means used to inform potential customers about the availability of goods and services. ${ }^{119}$

As mentioned above, it is safe to assume that employment ads fall within employment non-discrimination protections and are thus a lex specialis to the Gender Access Directive. ${ }^{120}$ Unlike other types of ads concerned with goods and services, gender-based discrimination is therefore not allowed in employment advertising, unless it constitutes a "genuine occupational requirement." ${ }^{121}$ At the same time, it is unclear how this would relate to ads aimed to inform audiences about housing or credit, since this is also covered in the Gender Access Directive, which allows gender discrimination in relation to advertising. Evelyn Ellis and Philippa Watson believe that "[s]uppliers of goods and services can therefore target their advertising to either men or

117. Celis, Mehrotra \& Vishnoi, supra note 45, at 3; Merrill \& Tobin, supra note 47.

118. For a general discussion on how and to what extent intermediaries for online ads are liable, see Philipp Hacker, Teaching Fairness to Artificial Intelligence: Existing and Novel Strategies Against Algorithmic Discrimination Under EU Law, 55 COMMON MKT. L. REV. 1143, 1162-64 (2018) (criticising the lack of transparency in financial and insurance decisions).

119. Similar concerns have been raised by a Greek expert who explains that "the 'vague' exclusion of 'the content of media and advertising' 'cannot mean that offers of and information on supply of goods and services in the media are excluded, the more so as the directive concerns goods and services available to the public." "SUSANNE BURRI \& AILEEN McColgan, Sex Discrimination in the Access to and Supply of Goods and SERViCES AND THE TRANSPOSITION OF DireCtive 2004/113/EC 17 (2009).

120. Lex specialis derogat legi generali means "special law repeals general laws." See AARON X. FELLMETH \& MAURICE HORWITZ, GUide to LATIN IN INTERNATIONAL LAW 177 (OXFORD UNIV. PRESS 2009).

121. "Genuine occupation requirement" is a common concept across the European Union that features non-discrimination Directives in the realm of employment. 
women but must supply the goods or services advertised to both sexes on the same terms."122 However, Eugenia Caracciolo di Torella is concerned that there is a "challenge of distinguishing 'goods' (included in the Directive) from 'advertisement of goods' (not included in the Directive)." gaps mean that the Gender Access Directive cannot entirely prevent stereotypical, offensive, and sexist advertising. ${ }^{124}$

Lastly, E.U. law does not offer protection against discrimination based on religion or belief, age, sexual orientation, or disability when offering goods and services. Once again, Member State law can establish (and sometimes has) higher levels of protection. ${ }^{125}$ For example, some Member States grant higher protection for gender inequality in areas such as media, advertisement, and education. ${ }^{126}$ The downside of this situation is that a harmonized standard for non-discrimination does not exist at the European level. ${ }^{127}$

\section{CURRENT CHALLENGES AND FUTURE OPPORTUNITIES FOR E.U. NON-DISCRIMINATION LAW AND AFFINITY PROFILING}

Thus far, this Article has analyzed privacy and discrimination problems associated with affinity profiling. By claiming not to collect or infer sensitive personal data, but rather to only assume an affinity or interests, companies might not need to adhere to the higher protection afforded to sensitive data processing in Article 9 of the GDPR. The lack of comprehensive nondiscrimination law in Europe further erodes the protection available to data subjects against affinity profiling. The law applies to a limited number of protected grounds and contexts. ${ }^{128}$

The applicability of direct discrimination to affinity profiling leaves much to be desired. If courts and regulators do not view affinity profiling as using

122. ElLis \& WATSON, supra note 12 , at 368.

123. Eugenia Caracciolo di Torella, The Principle of Gender Equality, the Goods and Services Directive and Insurance: A Conceptual Analysis, 13 MAASTRICHT J. EuR. COMP L. 339, 343 (2006).

124. See Burri \& MCCOlgan, supra note 119, at 6. For a strong criticism of these exemptions, see Caracciolo di Torella, supra note 123, at 343 ("Although the unequal treatment in these fields has been justified in light of its clash with the fundamental right to freedom of expression, it is difficult to envisage how the exploitation of women in the media can be regarded as a fundamental right.").

125. For an overview of this protection, as well as in relation to offensive, sexist advertisements and Member State law, see generally BURRI \& MCCOLGAN, supra note 119.

126. Eur. PARLIAMENTARY ReSEARCH SERV., supra note 111, at I-38. The handbook also provides an overview of how the Member States have implemented the framework.

127. For an overview of the fragmented standards across the E.U. Member States, see generally Isabelle Chopin, Carmine CONTE \& EDITH Chambrier, European Commission, A Comparative Analysis of Non-Discrimination LaW in Europe (2018).

128. See supra Sections III.B.1-III.B.4. 
protected attributes or accepted proxies, people possessing these attributes may not be able to raise direct discrimination claims. Even if affinity profiling is interpreted as directly using protected traits, the related argument that inferring an affinity for a protected group (e.g., "affinity for African American culture") is completely different than inferring that the user has certain protected attributes (e.g., "African American") still creates problems for potential claimants. If this argument is accepted, individuals subject to affinity profiling would not be able to raise direct discrimination claims because a protected attribute has not been directly inferred; rather, only an affinity with that attribute had been inferred. Even if these legal hurdles are overcome, the claimant might not want to openly acknowledge that they possess a particular protected trait (e.g., sexual orientation or religion) when bringing a discrimination claim. And finally, people who are subjected to discriminatory ads based on an inaccurate classification or grouping may not receive any protection, as they do not possess the trait protected by non-discrimination law (e.g., men that are shown discriminatory ads intended for women).

Indirect discrimination provides a promising alternative route to raise claims against advertisers. Targeting source or "look alike" audiences, while not based on protected grounds, can still lead to differential results for protected groups. For example, excluding people from seeing ads based on their assumed interest in part-time work could lead to differential results, if it can be shown that a large portion of part-time workers are women.

In these cases, members that share these attributes could bring a claim provided that the other conditions have been established, such as the existence of a comparison group, adverse and less favorable treatment, causality, and a lack of justification. ${ }^{29}$ Apart from the challenge of gathering the evidence necessary to meet the conditions for a claim, two additional problems remain. First, claimants might not want to openly and publicly discuss their sensitive attributes. Second, as with direct discrimination, people that were served the discriminatory ads but do not share the attributes of the target audience (e.g., employment ads aimed at gay users that are unintentionally shown to a straight user due to algorithmic misclassification of sexual orientation) may not be eligible to make a claim because they are not a member of the protected group. The next Section discusses how the concept of discrimination by association can be used to address this gap in legal protections against affinity profiling.

129. See infra Sections IV.B.1-IV.B.2, IV.C. 


\section{DISCRIMINATION BY ASSOCIATION AND AFFINITY PROFILING}

The legal concept of discrimination by association may offer a way forward. Discrimination by association is a type of discrimination which has been recognized by the ECJ, the European Court of Human Rights (ECHR), national courts, ${ }^{130}$ and Member State laws. ${ }^{131}$ Applying this concept to advertising would solve many of the weaknesses of discrimination law in the context of affinity profiling outlined above. Two landmark judgments of the ECJ have important implications for OBA by allowing claimants to appeal to direct or indirect discrimination by association.

\section{A. Direct Discrimination by Association: The Coleman Case}

Discrimination by association was first proposed by the ECJ in the 2008 case Coleman v. Law. ${ }^{132}$ According to the court, protections against direct discrimination apply not only to people who possess the protected characteristics in question, but also to people who experience discrimination because of their association with the protected group. ${ }^{133}$

In Coleman, claimant, Ms. Coleman, sued her employer for not agreeing to give her more flexible working hours to take care of her disabled child and for eventually terminating her. ${ }^{134}$ She compared herself with a group of other parents in the firm who had been granted such privileges for their non-disabled children. ${ }^{135}$ She claimed to be discriminated against in the workplace because of her child's disability. ${ }^{136}$ The court agreed, ruling that her treatment constituted direct discrimination on the basis of her child's disability. This type of discrimination constitutes direct discrimination by association. ${ }^{137}$ According

130. See, e.g., English v. Thomas Sanderson Ltd [2008] EWCA (Civ) 1421 (Eng.) (holding that homophobic banters against a heterosexual man was discrimination protected by antidiscrimination provisions); Szczegóły orzeczenia v. Ca 3611/14 - Portal Orzeczeń Sądu Okręgowego w Warszawie (addressing discrimination in relation to sexual orientation in Poland); Eur. Union AgEnCy FOR Fundamental RightS \& COUNCIL OF EuR., supra note 98 , at 51-52.

131. For an overview and an example of the Member States laws on discrimination by association or by assumption/perception, refer to Austria's discrimination based on assumed friendship with someone who possesses a protected attribute is illegal. See generally CHOPIN, CONTE, \& CHAMBRIER, supra note 127, at 44-46.

132. Coleman, supra note 15.

133. See id. at $₫ 63$.

134. Id. at 926.

135. Id.

136. Id. (citing to Articles 2(1)-(3) of the Directive 2000/78/EC).

137. See id. at 56. Note that the Court never uses this term. See Bell, supra note 116, at 8. For a view that the judgment created the concept of direct (but not indirect) discrimination by association, see Andrea Eriksson, European Court of Justice: Broadening the Scope of European 
to this concept, a claimant does not need to possess a protected attribute herself, but rather merely suffer the consequences of the discriminatory behavior which is based on her relationship with her child, or the person(s) possessing the protected attribute. ${ }^{138}$ The court arguably did not limit discrimination by association to disability because the rationale of the Employment Directive is to combat all types of discrimination in the workplace. ${ }^{139}$

Coleman marks a significant turning point for non-discrimination law. It shows that, "[n]ot only does [non-discrimination law] protect the person with a protected characteristic (race, sex, disability), it also shields somebody who does not but is associated with such a person." ${ }^{140}$ Claimants therefore do not need to be part of a protected group but need only experience the adverse effects directed at the group..$^{141}$

What does discrimination by association mean for OBA? This will depend on whether one deems the interest group in which users are placed to be close enough to the classes protected in E.U. non-discrimination Directives. For example, is "Hispanic affinity"142 close enough to "race" or "ethnicity" within the meaning of the Racial Equality Directive? Is the interest category "Vogue readers" close enough to "sex" in the sense of the Gender Equality Directive?

Nondiscrimination Law, 7 INT. J. CONST. L. 731, 751-52 (2009); Gabriel von Toggenburg, Discrimination by Association: A Notion Covered by EU Equality Law?, 3 EUR. L. REP. 82, 86 (2008).

138. Coleman, supra note 15, at 1 61(1).

139. Id. at 50 ("Although, in a situation such as that in the present case, the person who is subject to direct discrimination on grounds of disability is not herself disabled, the fact remains that it is the disability which, according to Ms Coleman, is the ground for the less favourable treatment which she claims to have suffered. As is apparent from paragraph 38 of this judgment, Directive 2000/78, which seeks to combat all forms of discrimination on grounds of disability in the field of employment and occupation, applies not to a particular category of person but by reference to the grounds mentioned in Article 1."). For a similar analysis of Coleman, see Marcus Pilgerstorfer \& Simon Forshaw, Transferred Discrimination in European Law: Case C-303/06, Coleman v Attridge Law; [2008] ICR 1128, [2008] IRLR 722 (ECJ), 37 INDUST. L.J. 384, 392-93 (2008); Bell, supra note 116, at 8. For an analysis in favor of the Coleman approach, see Eriksson, supra note 137, at 751. For a view that only direct discrimination by association exists (and not indirect), and only in areas such as disability, see Catalina-Adriana Ivanus, Discrimination by Association in European Law, 2 PERSP. Bus. L.J. 116, 121 (2013).

140. Catalina-Adriana Ivanus, supra note 139, at 117.

141. It has been criticized that the Court did not define the required relationship/ closeness of the victim and the protected group to fall under this concept. See Eriksson, supra note 137 , at 751 .

142. Dexter Thomas, Facebook Tracks Your "Ethnic Affinity" - Unless You're White, VICE NEws (2016), https://www.vice.com/en_us/article/paqeez/facebook-tracks-your-ethnic -affinity-unless-youre-white. 
In relation to ethnicity, the ECJ ruled in a separate case that the "concept of ethnicity ... has its origin in the idea of societal groups marked in particular by common nationality, religious faith, language, cultural and traditional origins and backgrounds ...."143 Elsewhere, the ECJ stated that this will not be the case if characteristics that do not link to any of these traits (e.g., country of birth) are used. ${ }^{144}$ The court explained that it "cannot be presumed that each sovereign State has one, and only one, ethnic origin," 145 meaning the country of birth is not a proxy for ethnicity.

The scope of the Racial Equality Directive has caused heated debates and its interpretation and transportation also greatly differs across the Member States. ${ }^{146}$ This is one of the reasons that Ellis and Watson have argued that courts and regulators should classify less favorable treatment based on color as direct discrimination based on ethnicity. ${ }^{147}$ Meanwhile, it is unclear whether or not language could be seen as an attribute that leads to indirect discrimination. ${ }^{148}$

If one wishes to argue that these interest groups do not map onto protected groups in the law, direct discrimination cases will not be possible. The avenue through indirect discrimination would, however, still be available for plaintiffs targeted by affinity advertising. ${ }^{149}$

If, conversely, one wishes to argue that affinity profiling does correspond to protected traits, direct discrimination claims are-in general-possible. However, if it is argued that advertisers are not directly using or inferring protected traits of an individual, but only assuming a person's interests in the protected group, direct discrimination claims would not likely be possible. In other words, the argument made is this: advertisements are shown to you based not on your ethnicity, but rather on your interest in a given ethnicity.

Still, even if this argument is accepted, discrimination by association can offer a solution. Individuals who experience an adverse action based on their association with a protected group could receive protection based on assumed

143. CHEZ, supra note 16, at 94.

144. Case C-668/15, Jyske Finans A/S v. Ligebehandlingsnævnet ex rel Huskic, ECLI: EU:C:2017:278, \ 33 (Apr. 6, 2017).

145. Id. at 21.

146. See CHOpin, CONTE \& CHAMBrier, supra note 127, at 15-16.

147. ELLIS \& WATSON, supra note 12, at 167.

148. See Case C-391/09, Runevič-Vardyn v. Vilniaus miesto savivaldybès administracija 2011 E.C.R. I-03787, \ 94 (holding that refusing to use the claimant's national language falls outside the Racial Equality Directive, as it does not constitute a service, without addressing the issue of indirect discrimination).

149. See supra Section III.B. 
interests (or assumed association) with a protected group, without the need to be a member of it. ${ }^{150}$

An important implication of discrimination by association is that it allows associated individuals to raise a discrimination claim against actions based on their assumed interests, rather than just actions based on their protected traits. Moreover, claimants can do so regardless of whether they are actually a member of the discriminated group. Arguably, individuals who are actually members of the group could also take this path, meaning they would not need to prove or publicly declare their membership in the group. ${ }^{151}$ This approach would be extremely valuable for claimants that might prefer not to publicly disclose their sensitive traits (e.g., religion, disability, or sexual orientation).

Discrimination by association could increase algorithmic accountability in advertising cases in several ways. First, if affinity profiling is seen as directly using protected traits, it could constitute direct discrimination (or by association). This means legal justification is only possible if the aforementioned non-discrimination directives explicitly name a possible exception.

Second, the concept of discrimination by association could widen the circle of potential claimants which could help support legal battles against unlawful discrimination. If direct discrimination occurred against, for example, a religious group, then Christians who have been misclassified as Buddhists could also make a claim as victims of direct discrimination (by association) if they experienced adverse treatment. ${ }^{152}$ It would also strengthen the relationship of allies of civil rights movements (e.g., LGBTQ+, religious, and women's). Fearing potential negative consequences based on associating with the groups could have an undesirable chilling effect.

Third, discrimination by association has practical advantages for claimants who are in fact part of a protected group and feel unlawfully treated, but do not want to "out" themselves in order to bring a claim. Since membership is not a precondition to warrant protection, affected parties could bring a claim

150. See Coleman, supra note 15.

151. The Polish Court used a similar argument in relation to a gay worker who was dismissed because he attended the Pride parade. See Szczególy orzeczenia v. Ca 3611/14 Portal Orzeczeń Sądu Okręgowego w Warszawie.

152. If one wishes to argue that affinity profiling is assuming that someone is, for example, Christian (rather than thinking they are interested in this religion) when in fact they are not, the concept of discrimination by perception could apply. The legal consequences are the same for discrimination by association and perception. See, e.g., Erica Howard, EU Equality Law: three recent developments, 17 EuR. L.J. 785, 800 (2011). (arguing that "discrimination by assumption" can be read into the Directives based on the Coleman judgment). 
under discrimination by association instead of appealing to normal direct discrimination, which might require publicly disclosing sensitive attributes.

Finally, as is generally true of direct discrimination cases, an abstract victim is sufficient to shift the burden of proof from the claimant to the accused; an actual victim does not need to be identified. This means that if a certain practice is discriminatory, it does not matter whether the practice actually had negative effects. ${ }^{153}$ For example, prima facie direct discrimination has been seen in advertisements against recruiting immigrants ${ }^{154}$ and in public statements against recruiting gay football players. ${ }^{155}$ In these cases, an identifiable victim was not required to prove prima facie direct discrimination. It was not necessary to demonstrate that fewer immigrants or fewer gay people applied for the job for the claims of discrimination to be successful.

B. Indirect Discrimination by Association: The CHEz Case

Coleman established direct discrimination by association as a standard concept in non-discrimination law. ${ }^{156}$ As mentioned before, it could be argued that major companies do not use protected attributes to make decisions or serve advertisements, but rather use affinity or assumed interests which are not equivalent to protected traits in non-discrimination law.

However, it is problematic to see affinity profiling as completely different from the usage of protected traits. This is because affinity or interests (e.g., friends, likes, ${ }^{157}$ and groups) can potentially reveal or correlate with protected attributes of a user. These interest groups could be proxies for a user's sensitive characteristics and personal life without the user being aware. For example, research suggests that friends are a strong indication of identity and even sexual orientation. ${ }^{158}$

153. See Case C-54/07, Centrum voor gelijkheid van kansen en voor racismebestrijding v. Firma Feryn NV, 2008 E.C.R. I-397, \ 40 ("[S]anctions ... must be effective, proportionate and dissuasive, even where there is no identifiable victim."); see also Case C-81/12, Asociația Accept v. Consiliul Național pentru Combaterea Discriminării, ECLI:EU:C:2013:275, ๆ 62 (Apr. 25, 2013) (holding that "sanctions ... must also be effective, proportionate and dissuasive, regardless of whether there is an identifiable victim").

154. Case C-54/07, 2008 E.C.R. I-397, supra note 153, at 19 2, 18(4)(d), 41(3).

155. C-81/12, Asociația Accept v. Consiliul Național pentru Combaterea Discriminării, Case 2013 E.C.R. I-275, 1 भी 35(1), 62.

156. See supra Section IV.A.

157. Kosinski, Stillwell \& Graepel, supra note 8, at 5802.

158. On how friends of friends can be used to infer personality traits, see generally Kristen M. Altenburger \& Johan Ugander, Monophily in Social Networks Introduces Similarity Among Friendsof-Friends, 2 NATURE Hum. BeHAV. 284 (2018); see also Carter Jernigan \& Behram F. T. Mistree, Gaydar: Facebook Friendships Expose Sexual Orientation, 14 FIRST MONDAY (2009), https:// doi.org/10.5210/fm.v14i10.2611. 
Even if one sees affinity groups as distinct from groups with protected traits, indirect discrimination as well as indirect discrimination by association might still occur. Furthermore, it may be possible to treat discriminatory OBA as direct discrimination (by association) where almost no legal justification exists. This could potentially pose legal challenges for advertisers in the future.

Indirect discrimination by association was introduced in a case heard by the ECJ in 2015, CHEZ Razpredelenie Bulgaria AD v. Komisia za zashtita of diskriminatsi. ${ }^{159}$ With this landmark judgment, the court established the notion that a claimant can sue for indirect discrimination by association despite neither being part of the protected group nor having a close relationship with it. The case centered around Ms. Nikolova, a shop owner in Bulgaria. Her establishment was situated in a primarily Roma populated area. Ms. Nikolova herself was not of Roma descent. ${ }^{160}$ She felt discriminated against because her electricity meters were situated at an unreachable height of six meters above the ground. This made it impossible for her to monitor her electricity consumption. ${ }^{161}$ The reason for installing the meters at this height was to prevent tampering. ${ }^{162}$

Indirect discrimination occurs if a protected group is treated significantly less favorably as a result of an " 'apparently neutral' provision, criterion or practice" 163 (e.g., meter installation) which do not explicitly use protected attributes. Ms. Nikolova claimed that, in areas where the majority of the population was not of Roma descent, the electricity meters were situated significantly lower to the ground. ${ }^{164}$ The court found that there was differential treatment in offering goods and services based on race or ethnicity, ${ }^{165}$ and that although Ms. Nikolova was not of Roma descent, she had been discriminated against.

Michael Malone has convincingly argued that this case has born the notion of indirect discrimination by association. ${ }^{166}$ Similar to Coleman, Malone argues

159. CHEZ, supra note 16.

160. Id. at 49.

161. Id. at 9 ๆ $22-29$.

162. Id. at 113; Michael Malone, The Concept of Indirect Discrimination by Association: Too Late for the UK?, 46 INDUS. L.J. 144, 145 (2017) (discussing the obvious stigma and implication that tampering would otherwise occur).

163. CHEZ, supra note 16, at $\$ 109$ (internal citations omitted).

164. Id. at 9 ๆ $22-23$.

165. For a better understanding of the law applied by the court in Coleman, see Council Directive 2000/43/EC, supra note 14, at art. 3(1)(h).

166. See Malone, supra note 162, at 150-51; see also Erica Howard, EU Anti-Discrimination Law: Has the CJEU Stopped Moving Forward?, 18 InT'L. J. DisCRIMINATION \& L. 60, 65 (2018) (arguing that Chez and Coleman also prohibit "discrimination by perception," which means 
that the claimant in CHEZ does not need to be part of the stigmatized collective to suffer discrimination. Moreover, the claimant does not even need to have a close relationship with the community. Rather, Malone explains that any "third-party damage" suffered from indirect racial discrimination entitles the victim(s) to protection. ${ }^{167}$ Initially, as in Coleman, the Advocate General (AG) in CHEZ referred to some sort of relationship with the stigmatized community (i.e., "wholesale and collective character"), ${ }^{168}$ but this restriction did not appear in the final judgment. ${ }^{169}$ It can therefore be assumed that no personal relationship is needed to warrant protection. ${ }^{170}$

The significance of the judgment in Chez goes further than establishing indirect discrimination by association. The court left open the possibility that the practice in question (meter installation) could be direct discrimination by association. A decision on this classification was ultimately left to the national court. ${ }^{171}$ Leaving this issue open is significant because the boundaries between direct and indirect discrimination can easily blur, and offenders are not likely to admit illegal reasons are behind their actions. ${ }^{172}$

What does this mean for affinity profiling? Advertisements based on the correlation of interests could lead to undesired differential results for protected groups. Platform providers may not actually be interested in inferring sensitive attributes, but rather merely want to identify correlations in the interests of their users. To use a stereotypical example, if a user visits jazz or blues websites, they might also see ads for Caribbean food. The decision to show food advertisements is not based on "race" or "ethnicity," but rather on the statistical correlation that suggests that people who have an interest in a certain type of music also enjoy a certain type of food. The decision to show jazz enthusiasts advertisements for Caribbean food can be seen as an "apparently

"discrimination because someone perceives a person to be, for example, of a particular ethnic origin or sexual orientation, when they are not").

167. See Malone, supra note 162, at 151.

168. Case C-83/14, Kokott, CHEZ Razpredelenie Bulgaria AD v. Komisia za zashtita ot diskriminatsia, Advisory Opinion, ECLI:EU:C:2015:170, ๆๆ 58, 60 (Mar. 12, 2015).

169. See Malone, supra note 162, at 151.

170. See Rossen Grozev, A Landmark Judgment of the Court of Justice of the EU-New Conceptual Contributions to the Legal Combat Against Ethnic Discrimination, 15 EQUAL RIGHTS REV. 168, 173 (2015).

171. CHEZ, supra note 16, at $129(4)$; McCrudden, supra note 90.

172. See, e.g., FARKAS \& O'DEMPSEY, supra note 93, at 38 ("[T] he CJEU has identified as direct discrimination cases in which a formally neutral rule (internal or legal) in fact affects one group only. In Nikoloudi, the CJEU examined a rule that reserved established staff positions to persons with full time jobs."); see also id. at 41 (addressing discrimination based on pregnancy, which is now considered a form of direct discrimination). 
neutral provision, criterion or practice." ${ }^{173}$ Nonetheless, unlawful differential results could still occur if statistical evidence shows that an interest in Caribbean food and jazz music is more likely to occur among a particular ethnic group and this group is treated less favorably than others without any justification (more on that below). ${ }^{174}$

Such correlations are not unrealistic. As mentioned above, research suggests that personal interests and friends are a strong indication of one's personality. ${ }^{175}$ These sources paint a very privacy-invasive picture and reveal or correlate with sensitive traits such as sexual orientation. ${ }^{176}$

The ECJ's judgments in Coleman and CHEZ have important consequences for OBA. If affinity profiling is not seen as inferring or using protected traits because the interest groups are seen as sufficiently distinct from protected categories such as "race" and "ethnicity" as described in the directives, no claims against direct discrimination could be brought. However, claims under indirect discrimination are possible if it can be shown that actions based on assumed affinity or interest groups lead to adverse and differential results for a protected group (and anyone associated with this group) in comparison with others in a similar situation.

Based on this reasoning, both claims under indirect discrimination as well as indirect discrimination by association are then possible. This could have interesting implications for OBA. First, as revealed in Coleman, it is not necessary for the claimant to be part of the disadvantaged group (e.g., men being shown advertisements for lower paying jobs because they have been classified as women). Likewise, as revealed in CHEZ, the claimant also does not need to have a close relationship with the protected group (e.g., she does not need to be an active member of the women's movement). However,

173. This term is used in all E.U. non-discrimination directives. See, e.g., Council Directive 2000/43/EC, supra note 14, at art. 2(2)(b).

174. It is important to note that is still unclear whether intermediaries such as Facebook and Google will be liable for discriminatory advertisement and to what extent. However, some scholars have argued that liability could extend to internet companies. See Philipp Hacker, Teaching fairness to artificial intelligence: Existing and novel strategies against algorithmic discrimination under EU law, 55 COMMON MARK. L. REV. 1143, 1164-65 (2018) (arguing that intermediaries can be liable drawing similarities between the responsibilities of Uber as an internet service provider); Jennifer Cobbe \& Jatinder Singh, Regulating Recommending: Motivations, Considerations, and Principles, 10 Eur. J.L. TECH. 1 (2019) (arguing that liability can be assumed when illegal content is recommended); David Jacobus Dalenberg, Preventing discrimination in the automated targeting of job advertisements, 34 COMPUT. L. SECUR. REV. 615, 626 (2018) (suggesting that ad tech companies will be liable for discriminatory advertisement).

175. See Kosinski, Stillwell \& Graepel, supra note 8, at 5802; Altenburger \& Ugander, supra note 158 , at 284 .

176. See Jernigan \& Mistree, supra note 158. 
widening the circle of potential claimants could also have the positive side effect of strengthening the claimants' relationship with stigmatized groups. Moreover, not granting protection to third parties could have an undesirable chilling effect due to fear over potential negative consequences from associating with these groups (e.g., people moving away from Roma populated areas).

Second, as argued above, the logical conclusion of not needing to be a member of the protected group to bring a successful claim is that a person who is in fact a member of the protected group does not need to prove it or "out" themselves.

Third, because the ECJ left open in CHEZ whether direct or indirect discrimination by association occurred, ${ }^{177}$ it may also be possible to classify the practice of placing ads based on affinity as direct discrimination (or by association) with almost no justification as discussed in Section IV.C. This could pose legal challenges for many advertising practices.

Of course, as discussed above, to bring a successful discrimination claim, a claimant must still demonstrate that they have suffered a particular disadvantage, identify a comparator that is treated more favorably, and demonstrate a disproportionately negative effect on a protected group. An indication of less favorable treatment in advertising could be seen in differential pricing or exclusion from goods and services or jobs, which is discussed in the next Section.

\section{Particular Disadvantage That Is Significantly More Negative in Its Effects on a Protected Group}

To bring a successful claim, a particular disadvantage must occur for one of the protected groups in comparison to a particular person or group in a similar situation in a protected sector: employment, welfare, or goods and services. Interestingly enough, the ECJ explained that "particular disadvantage' within the meaning of that provision does not refer to serious, obvious or particularly significant cases of inequality, but denotes that it is particularly persons of a given racial or ethnic origin who are at a disadvantage because of the provision, criterion or practice at issue . . ." "178 The low bar for the notion of "particular disadvantage" is very relevant for cases of discriminatory advertisements which might otherwise be seen as trivial.

Conversely, some Member State case law suggests that a certain threshold of disadvantage must be met. The implementation assessment of the Gender

177. See generally CHEZ, supra note 16.

178. Id. at I 109; see also Grozev, supra note 170, at 175 (explaining that "particular disadvantage" and "less favourable treatment" should be seen as comparable in their severity). 
Access Directive states that the issue of differential pricing is underexplored because it is sometimes seen as "trivial." " For example, in Sweden, differential prices for haircuts for men and women are seen as "trivial" issues. ${ }^{180}$ Furthermore, despite the ECJ having struck down a provision in the Gender Access Directive in 2012 that allowed insurance companies to have different prices based on gender, ${ }^{181}$ some Member States such as Estonia, Hungary, and (to a lesser degree) Finland still allow these practices. The European Commission has expressed concern that such national provisions do not comply with the ECJ's ruling. ${ }^{182}$

Another potential standard for defining "particular disadvantage" can be found under the GDPR. In the context of data protection law and the safeguards around automated decision-making with legal and significant effects (Article 22 of the GDPR), the Working Party explained that price discrimination can be seen as a type of automated decision that impacts individuals significantly. ${ }^{183}$ Data subjects receive additional protection under data protection law on this basis. Potential parallels can be found between E.U. non-discrimination law and the notion of "particular disadvantage," and the Working Party's concept of legal and significant effects (e.g., differential pricing especially credit, health, or decisions relating to education or employment) in the GDPR. ${ }^{184}$ Thus, discriminatory advertisements as described in the Working Party's February Guidelines on automated decisionmaking could be interpreted as a type of particular disadvantage.

Despite this, practical challenges remain. Individuals are often unaware that they are discriminated against. In the offline world this might be a simpler problem. Consumers, for example, have the ability to compare prices in different stores. Similarly, consumers would know if a vendor refuses to sell products to them. In the online world, discriminatory treatment can be much harder to observe. Consumers may not know whether they or others have been

179. Eur. Parliamentary ReSEARCH SERV., supra note 111, at I-38.

180. Id. at I-36.

181. Case C-236/09, Association belge des Consommateurs Test-Achats ASBL v. Conseil des ministres, ECLI:EU:C:2011:100, 1 \ 30-34 (Mar. 1, 2011); see also Schiek, supra note 108, at 436 (criticizing this provision by stating: "One of the purposes of equality law is deeply individualistic: no one shall be judged on the basis of assumptions in line with group characteristics. Again, the insurance argument is a perfect test case"); Guidelines on the Application of Council Directive 2004/113/EC to Insurance, in the Light of the Judgment of the Court of Justice of the European Union in Case C-236/09 (Test-Achats), I 14, 2012 O.J. (C 11) 1, 3 (EU) (explaining that some gender-based differences in premiums are still possible).

182. EUR. PARLIAMENTARY RESEARCH SERV., supra note 111, at I-23.

183. Art. 29 WP Feb. Guidelines, supra note 6, at 22.

184. Id. at 21-22. 
offered a better price or (not) shown ads, or if they have been excluded from the market.

Further, it is also not clear if online advertising constitutes "a particular disadvantage" in the sense of the regulation. The court explained in Chez that the threshold should not be situated too high: " $[\mathrm{P}]$ articular disadvantage' within the meaning of [Article 2(2)(b) of Directive 2000/34] does not refer to serious, obvious or particularly significant cases of inequality, but denotes that it is particularly persons of a given racial or ethnic origin who are at a disadvantage because of the provision, criterion or practice at issue ...."185 Nonetheless, the ephemeral nature of online advertising may not be comparable to a long-lasting systemic inequality. On the other hand, while a particular ad might be ephemeral, the ad delivery system is not and could exhibit systematic bias and is evidence of "persistent and relatively constant disparity over a long period ...."

Without algorithmic transparency and more transparent business models, it will be hard for claimants to prove prima facie discrimination and thus shift the burden of proof to the alleged offender. ${ }^{187}$ This could prove to be a great challenge in the future as previous cases show that applicants are not necessarily entitled to confidential information (in this case personal data of another job applicant) in order to prove non-discrimination claims. ${ }^{188}$

\section{Disproportionately Affected in a Negative Way (A Comparator)}

In addition to demonstrating that a particular disadvantage occurred, the claimant needs to find a group that is treated more favorably. This means that the claimant must show that the disputed measure negatively affected "far

185. CHEZ, supra note 16 , at 9109 .

186. See Case C-167/97, Regina v. Secretary of State for Employment, ex parte SeymourSmith, 1999 E.C.R. I-666, \61.

187. See Philipp Hacker, Teaching Fairness to Artificial Intelligence: Existing and Novel Strategies Against Algorithmic Discrimination Under EU Law, 55 Common MKT. L. ReV. 1143, 1145, 116264 (2018) (criticizing the lack of transparency in financial and insurance decisions).

188. Case C-104/10, Kelly v. Nat'l Univ. of Ireland, 2011 E.C.R. I-06813, ๆ 39. This case is interesting insofar as the court acknowledges that the lack of access is a problem. FARKAS \& O’DempSEY, supra note 93, at 28-29; see also Case C-415/10, Meister v. Speech Design Carrier Sys. GmbH, ECLI:EU:C:2012:217 (Apr. 19, 2012) (a similar case where the court stated that while the applicant did not have a right of access to information on the person hired for a job from which she was rejected, the refusal to share any information by the alleged offender could have been interpreted as prima facie discrimination, causing the burden of proof to shift: this issue was left for the national court in Germany to decide, and the court ultimately rejected the claim). 
more woman than men"189 or a protected group "far more" 190 than others in a similar situation.

Unfortunately, European case law varies noticeably in this regard. ${ }^{191}$ For example, in a Spanish case in relation to part-time work, the ECJ acknowledged that if $80 \%$ of the affected group are women, the adverse action constitutes discrimination. ${ }^{192}$

The aforementioned study ${ }^{193}$ also shows the importance of statistics to prove differential results and refers to a summary of ECJ's jurisprudence that can be found in the AG Léger's opinion in the Nolte v. Landesversicherungsanstalt Hannover case: ${ }^{194}$

[ $\mathrm{n}$ order to be presumed discriminatory, the measure must affect "a far greater number of women than men" or "a considerably lower percentage of men than women" or "far more women than men" .... Cases suggest that the proportion of women affected by the measure must be particularly marked. In Rinner-Kübn, the Court inferred the existence of a discriminatory situation where the percentage of women was $89 \%$. In this instance, per se the figure of $60 \% \ldots$ would therefore probably be quite insufficient to infer the existence of discrimination. ${ }^{195}$

189. See Case C-1/95, Gerster v. Bayern, 1997 E.C.R I-5274, \ 30 ("According to settled case-law, indirect discrimination arises where a national measure, although formulated in neutral terms, works to the disadvantage of far more women than men"); see also Case C-123/ 10, Brachner v. Pensionsversicherungsanstalt, 2011 E.C.R. I-10044, \56; Case C-7/12, Riežniece v. Zemkopības ministrija, ECLI: EU:C:2012:410, | 39 (June 20, 2013) (addressing indirect discrimination on the grounds of sex); Case C-363/12, Z. v. Gov. Dep't, ECLI:EU:C:2014:159, 153 (Mar. 18, 2014).

190. Case C-123/10, Brachner v. Pensionsversicherungsanstalt, 2011 E.C.R. I-10044, 956 ("[a]ccording to the Court's settled case-law, indirect discrimination arises where a national measure, albeit formulated in neutral terms, works to the disadvantage of far more women than men"); Case C-385/11, Isabel Elbal Moreno v. Instituto Nacional de la Seguridad Social, ECLI:EU:C:2012:746, \} 2 9 \text { (Nov. 22, 2012); Case C-527/13, Fernández v. Instituto Nacional } de la Seguridad Social, ECLI:EU:C:2015:215, 928 (Apr. 14, 2015).

191. Sandra Wachter, Brent Mittelstadt \& Chris Russell, Why Fairness Cannot Be Automated: Bridging the Gap Between EU Non-Discrimination Law and AI (manuscript at 29-31) (Mar. 3, 2020), https://papers.ssrn.com/abstract $=3547922$ (discussing variability and imprecision in thresholds for particular disadvantage across E.U. case law).

192. Case C-385/11, ECLI:EU:C:2012:746, supra note 190, at ๆ甲 31-32 .

193. Eur. Union AGENCY FOR FundAMENTAL Rights \& COUNCIL OF EuR., supra note 98, at 242-48.

194. Case C-137/93, Nolte v. Landesversicherungsanstalt Hannover, Advisory Opinion, 1995 E.C.R. I-4627, 19 56-58.

195. Eur. UNION AGENCY FOR FundAMENTAL Rights \& COUNCIL OF EuR., supra note 98, at 242-43 (internal citations omitted). 
In relation to different rights for part-time workers, courts have found that potential discrimination was sufficiently proven in cases where $87.9 \%{ }^{196}$ or $87 \%{ }^{197}$ of part-time employees were women. The abstract danger of a protected group being affected at a large percentage was sufficient.

At the same time, the ECJ held in Regina $v$ Secretary of State for Employment, ex parte Nicole Seymour-Smith and Laura Perez that a measure which only allow appeals against unfair dismissal after two years of continuous employment, which affected $77.4 \%$ men and $68.9 \%$ women, did not amount to indirect discrimination against women's rights to appeal. ${ }^{198}$ It remains open whether an $80-90 \%$ threshold is normatively acceptable or desirable, or whether this threshold should be lower.

Practically speaking, in OBA, finding a comparable group that is significantly treated differently can be difficult due to a lack of transparency in algorithmic decision-making and business practices. Not knowing the optimization conditions or decision rules of algorithms make it difficult to prove a case. If, for example, an employer was to decide that only people taller than one meter and eighty centimeters should be hired, it would be easy to establish prima facie discrimination. ${ }^{199}$ In this case, the rule is well known (via hiring strategy) and thus it is easier to find statistical evidence to show that, while the rule does not directly use gender as a discriminating factor, it would nonetheless affect women disproportionately. In the online world, we often do not know the rules and attributes on which we are profiled and whether these attributes correlate with protected characteristics. We cannot be sure how our interests (e.g., music) correlate with protected attributes (e.g., gender), as we lack a full causal model of the world that would show us how this data relates to each other. ${ }^{200}$

Further, potential claimants do not know the makeup and size of their profiling group, which other groups exist, and how they are treated in comparison to those other groups. This makes it difficult to prove that a protected group was disproportionally negatively affected. Trade secrets and business secrecy have formed a strong barrier in the past to algorithmic

196. Joined Cases C-4/02 \& C-5/02, Schönheit v. Stadt Frankfurt am Main, 2003 E.C.R. I-583, 9ा 35, 63-64.

197. Case C-1/95, 1997 E.C.R I-5274, supra note 189, at 93.

198. Case C-167/97, 1999 E.C.R. I-666, supra note 186, \ๆ 63-65; see also Dalenberg, supra note 174 , at 623 .

199. Inspiration for this hypothetical was taken from a case heard by the Federal Labour Court in Germany. Bundesarbeitsgericht [BAG] [Federal Labor Court] Feb. 18, 2016, 8 [AZR] 638/14 (discussing Lufthansa's policy of only hiring pilots taller than $1.65 \mathrm{~m}$ ).

200. See Kusner et al., supra note 58; Russell et al., supra note 58, at 6397. 
accountability and fairness. ${ }^{201}$ To remedy this, more transparency is needed. Specifically, information must be made available to individuals and groups affected by OBA and affinity profiling concerning the composition of their profiling group(s) and the distribution of outcomes across the affected population. This information is essential for affected parties to define legitimate disadvantaged and comparator groups.

On the positive side, if a comparable group can be found (and a particular disadvantage occurred), the burden of proof is shifted from the claimant to the accused. Only prima facie discrimination must be shown to shift this burden, at which point the accused must prove lawful behavior.

This can be done in two ways. First, by demonstrating that there was no causal link between the prohibited ground and the differential treatment, meaning that the same effect would have happened if the claimant had a different age, gender, ethnicity, etc. ${ }^{202}$ Alternatively, the accused can show that even though differential treatment occurred, it was justified because a legitimate aim was pursued in a necessary and proportionate manner. ${ }^{203}$ If neither condition can be established, the alleged offender will be liable for discrimination, regardless of their actual intent. ${ }^{204}$

\section{JUSTIFICATION OF DisCRIMINATION}

Both direct and indirect discrimination can be justified under certain circumstances. Since differential treatments and results for protected groups can be lawful under certain circumstances, it is necessary to take a closer look at how discrimination can be justified. As discussed in Part III, direct discrimination is only lawful if it is explicitly named in the non-discrimination directives (e.g., genuine "occupational requirement" 205 or Recital 16 of the Gender Goods and Service Directive ${ }^{206}$ ) or in Member State law. Indirect

201. Sandra Wachter, Brent Mittelstadt \& Luciano Floridi, Why a Right to Explanation of Automated Decision-Making Does Not Exist in the General Data Protection Regulation, 7 INT'L. DATA PRIVACY L. 76, 85-89 (2017); see also Merrill \& Tobin, supra note 47 (discussing Facebook's efforts to prevent ad transparency tools from accessing information); but see ProPublica Data Store, COMPAS Recidivism Risk Score Data and Analysis, ProPublica DATA STORE (2016), https://www.propublica.org/datastore/dataset/compas-recidivism-risk-score-data-and -analysis (last visited May 7, 2019) (analyzing Northpointe's COMPAS algorithm for bias or unfairness).

202. ELLIS \& WATSON, supra note 12 , at 167 .

203. This is mentioned in all E.U. non-discrimination directives. See, e.g., Council Directive 2000/43/EC, supra note 14, at art. 2(2)(b).

204. Id.

205. E.g., Council Directive 2000/78/EC, supra note 14, at art. 4.

206. E.g., single-sex private clubs or single-sex sports events. 
discrimination is only lawful if a legitimate aim is pursued and the measure is necessary and proportionate. ${ }^{207}$

Unfortunately, European case law does not have a clear standard for what constitutes a legitimate interest. ${ }^{208}$ At a minimum, some economic justifications can be seen as legitimate. ${ }^{209}$ Courts have found economic justifications to be legitimate with respect to less strict employment labor laws to alleviate the burden for small businesses ${ }^{210}$ and to serve customer preferences, ${ }^{211}$ as well as in relation to the exclusion from the pension scheme based on objectively justified economic grounds. ${ }^{212}$ At the same time, the ECJ, on various occasions, has ruled that economic interests (e.g., cutting public expenditure ${ }^{213}$

207. As stated in all the E.U. non-discrimination directives.

208. For a strong critique of the broad possibilities of legitimizing indirect discrimination through the frameworks themselves (Article 2(2) of the Employment Directive) as well as the incoherence of the jurisprudence of the ECJ over the years, see ELLIS \& WATSON, supra note 12, at 409-18. For a further overview of the Court's accepted legitimate aims, see CHRISTA TOBler, Limits AND POTENTIAL OF THE CONCEPT OF INDiRECT DiscriminATION 33-35 (Christa Tobler \& Europäische Kommission eds., 2008).

209. See Case C-196/02, Nikoloudi v. Organismos Tilepikinonion Ellados AE, 2005 E.C.R. I-1812, 152 ("Even supposing that this last argument put forward by [defendant] seeks to assert a legitimate aim falling within policy on economic development and job creation, it nevertheless constitutes a mere generalisation insufficient to show that the aim of the measures at issue is unrelated to any discrimination on grounds of sex ....”).

210. See Case C-189/91, Kirsammer-Hack v. Sidal, 1993 E.C.R. I-6215, \ 35 (“[W] here it is not established that undertakings which are not subject to that system employ a considerably greater number of women than men. Even if that were the case, such a measure might be justified by objective reasons not related to the sex of the employees in so far as it is intended to alleviate the constraints weighing on small businesses.").

211. This was a direct discrimination case (which also needs a legitimate aim to be lawful) in relation to regulating the midwife profession. Case C-165/82, Comm'n of the Eur. Cmty. v. United Kingdom of Great Britain and Northern Ireland, 1983 E.C.R 3432, 20 (stating that provisions favoring women over man are justified because "[i]t must however be recognized that at the present time personal sensitivities may play an important role in relations between midwife and patient").

212. It was for the national court to decide if the measure corresponded to a real need is necessary and appropriate. The sole fact that this measure affected more women than men was not sufficient to claim indirect discrimination. See Case C-170/84, Bilka-Kaufhaus GmbH v. von Hartz, 1986 E.C.R. I-1620, ๆ 36.

213. For example, the aim of restricting public expenditure was not sufficient to justify differential treatment between men and women. See Joined Cases C-4/02 \& C-5/02, 2003 E.C.R. I-583, supra note 196, at 9 84. In a different case, it was found that budgetary considerations alone are not a legitimate interest. See Case C-196/02, 2005 E.C.R. I-1812, supra note 209, at $\$ 53$. For more details on economic justification, see Justyna MaliszewskaNienartowicz, Direct and Indirect Discrimination in European Union Law-How to Draw a Dividing Line?, 3 INT’L. J. SOC. SCI. STUD. 41, 44 (2014). 
or increasing $\operatorname{costs}^{214}$ ) cannot be the sole justification for discriminatory measures in the public sector. The ECJ has ruled similarly, albeit with less clarity, concerning the private industry, with respect to, for example, a policy of neutrality via a company's customers and customer satisfaction. ${ }^{215}$ Similarly, the court has rejected the argument that that the costs associated with rectifying inequality (i.e., a pay gap) can justify maintaining the status quo for both the private and the public sectors. ${ }^{216}$ Similarly, the court ruled that "while budgetary considerations may underpin the chosen social policy of a Member State and influence the nature or extent of the measures that that Member State wishes to adopt, such considerations cannot in themselves constitute a legitimate aim within the meaning of Article 6(1) of Directive 2000/78 . .."217

Of course, it can be argued that different standards might apply to public and private entities. However, it seems unlikely that the ECJ would allow a completely different interpretation of the Directives for the private industry compared to the public sector. ${ }^{218}$ It seems more likely that a fair balance of interests must be established that acknowledges that legitimate aims are

214. See Case C-243/95, Hill v. Revenue Comm'r, 1998 E.C.R. I-3759, \ 40 (“So far as the justification based on economic grounds is concerned, it should be noted that an employer cannot justify discrimination arising from a job-sharing scheme solely on the ground that avoidance of such discrimination would involve increased costs.").

215. In relation to customer complaints against employees providing IT services wearing a headscarf, see Case C-188/15, Bougnaoui, Association de défense des droits de l'homme (ADDH) v. Micropole SA, ECLI:EU:C:2017:204, \ 40 (Mar. 14, 2017) ("It follows from the information set out above that the concept of a 'genuine and determining occupational requirement', within the meaning of that provision, refers to a requirement that is objectively dictated by the nature of the occupational activities concerned or of the context in which they are carried out. It cannot, however, cover subjective considerations, such as the willingness of the employer to take account of the particular wishes of the customer."). However, it was for the national court to decide whether the action should be seen as indirect or direct discrimination, which has implications on possible justifications. See id. $\uparrow \uparrow$ 31-32. But see Case C-157/15, Achbita v. G4S Secure Sol. NV, ECLI:EU:C:2017:203, $\mid 37$ (Mar. 14, 2017) (“As regards, in the first place, the condition relating to the existence of a legitimate aim, it should be stated that the desire to display, in relations with both public and private sector customers, a policy of political, philosophical or religious neutrality must be considered legitimate."). However, it was for the referring court to decide if this measure is appropriate and necessary. See id. at 44.

216. See generally Case 43-75, Gabrielle Defrenne v. Société anonyme belge de navigation aérienne Sabena, 1976 E.C.R. I-455.

217. Case C-530/13, Schmitzer v. Bundesministerin für Inneres, ECLI:EU:C:2014:2359, If 41 (Nov. 11, 2014); see also Joint Cases C-159/10 \& C-160/10, Gerhard Fuchs v. Hessen, ECLI:EU:C:2011:508, 974 (July 21, 2011).

218. See TOBLER, supra note 208, at 6, 33 (claiming that budgetary reasons alone can never constitute a legitimate aim). 
different from budgetary reasons or competitiveness. ${ }^{219}$ In stark contrast, some reports suggested that " $[\mathrm{p}]$ urely budgetary (financial) considerations can never serve as objective justifications." 220

While the jurisprudence is inconsistent, the case law shows the court's preference for an overarching societal aim (e.g., social and employment policy ${ }^{221}$ ), rather than pure economic interests, when assessing what constitutes a legitimate aim. For example, the court accepted legitimate aims such as public safety in relation to the police force, ${ }^{222}$ more job security for people over the age of forty at the expense of younger people, ${ }^{223}$ integration of people without a secondary degree into the job market and higher education, ${ }^{224}$ forced retirement to offer job opportunities for the youth, ${ }^{225}$ age limitations for safety reasons, ${ }^{226}$ and compensation for career breaks to take care of children. ${ }^{227}$

219. See ElLIS \& WATSON, supra note 12, at 412 ("[L]egitimate aims are distinguishable from purely individual reasons particular to the employer's situation, such as cost reduction or improving competitiveness, although it cannot be ruled out that a national rule may recognize, in the pursuit of those legitimate aims, a certain degree of flexibility for employers.").

220. FARKAS \& O'DEMPSEY, supra note 93, at 37.

221. See Case C-173/13, Leone v. Garde des Sceaux, ECLI:EU:C:2014:2090, \ 53 (July $17,2014)$ (holding that a legitimate social-policy objective is a legitimate aim).

222. Access to posts and vocational training with firearms were restricted for women as they are more often the victims of assassinations. It was left to the national court to decide if the legitimate aim is pursued in a necessary and proportionate manner. See Case C-222/84 Johnston v. Chief Constable of the Royal Ulster Constabulary, 1986 E.C.R. I-206, 1 甲 35, 62.

223. Whilst the legitimate aim was lawful and shorter notice periods for people under the age of twenty-five were seen as justified, the provision was still unlawful because "the legislation is not appropriate for achieving that aim, since it applies to all employees who joined the undertaking before the age of 25, whatever their age at the time of dismissal." Case C-555/ 07, Kücükdeveci v. Swedex GmbH \& Co. KG., 2010 E.C.R. I-393, 甲ฯ 34, 40.

224. However, the provision was seen as not suitable to achieve this legitimate interest and thus deemed unlawful. See Case C-88/08, Hütter v. Technische Universität Graz, 2009 E.C.R. I-5327, ๆๆ 46, 50.

225. The case centered around dentists. Whether or not this measure was necessary and appropriate was left for the national court to decide. See Case C-341/08, Petersen v. Berufungsausschuss für Zahnärzte für den Bezirk Westfalen-Lippe, 2010 E.C.R. I-71, ๆๆ 68, 74.

226. In relation to maximum age for recruitment of firefighters, see Case C-229/08, Wolf v. Stadt Frankfurt am Main, 2010 E.C.R. I-1, ๆף 43-45, 48. However, this ruling is disputed and seen as controversial. See ELLIS \&WATSON, supra note 12, at 393. A different ruling stated that a maximum age for pilots is a legitimate aim; however, in this case lowering of the retirement age was seen as not necessary because public airlines had higher retirement ages and have to deal with the same safety issues. See Case C-447/09, Prigge v. Deutsche Lufthansa AG, 2011 E.C.R. I-8003, ๆๆ 68-69, 84 (2011). Note that both of these cases relate to direct discrimination based on age, but lawful direct discrimination also requires a legitimate aim.

227. In relation to better pension schemes (early retirement) for people that took career breaks, see Case C-173/13, ECLI:EU:C:2014:2090, supra note 221, at 104. 
Other legitimate aims according to Justyna Maliszewska-Nienartowicz include:

ensuring coherence of the tax system; the safety of navigation, national transport policy and environmental protection in the transport sector; protection of ethnic and cultural minorities living in a particular region; ensuring sound management of public expenditure on specialized medical care; encouragement of employment and recruitment by the Member States; guaranteeing a minimum replacement income; need to respond to the demand for minor employment and to fight unlawful employment. ${ }^{228}$

The promotion of full-time work has also been acknowledged as a legitimate interest of an employer, who used this interest to exclude part-time workers from a pensions scheme. ${ }^{229}$ Therefore, in these and similar cases, indirect discrimination can be justified if seen as both necessary and proportionate.

Even though the ECJ views social and employment policy as a legitimate aim, and grants Member States a higher margin of appreciation in this regard, ${ }^{230}$ it still requires that the measures enacting those policies be necessary and proportionate:

[m]ere generalisations concerning the capacity of a specific measure to encourage recruitment are not enough to show that the aim of the disputed rule is unrelated to any discrimination based on sex nor to provide evidence on the basis of which it could reasonably be considered that the means chosen were suitable for achieving that $\operatorname{aim}^{231}$

In Bilka-Kaufhaus GmbH v. von Hartz, the court provided more detail on the proportionality test. ${ }^{232}$ The court explained that, in relation to sex discrimination, the test has three steps. In order to justify indirect discrimination, the measures must "correspond to a real need on the part of

228. Maliszewska-Nienartowicz, supra note 213, at 44-45.

229. Case C-170/84, 1986 E.C.R. I-1620, supra note 212, at 937 . The argument was that part-time workers often refuse to work in the afternoon and on weekends. Id. at $\$ 33$. Unfortunately the court did not discuss whether this measure was necessary or proportionate.

230. Case C-317/93, Nolte v. Landesversicherungsanstalt Hannover, 1995 E.C.R. I-4650, ब1 33.

231. Case C-167/97, 1999 E.C.R. I-666, supra note 186, at 9 76; see also TOBLER, supra note 208 , at 6,35 (discussing the scope of legitimate aims in relation to justification of potential discrimination).

232. Case C-170/84, 1986 E.C.R. 1620, supra note 212, at 936. 
the undertaking, are appropriate with a view to achieving the objectives pursued and are necessary to that end ...."233

How does lawful justification apply to advertisements? The decision to show ads to people could be based on a "neutral provision, criterion or practice," ${ }^{234}$ such as geolocation. Companies may not, for example, have an explicit intention to use ethnicity as an excluding factor. Rather, discriminatory advertisements could be based on the assumed interests of a certain demographic, meaning the "neutral provision" was a business and optimization decision. However, differential results can still occur (e.g., certain ads (not) being shown), which are only lawful with an objective justification, and ideally not based on economic and business concerns (e.g., customer satisfaction, profit maximization) alone. Rather, as the court stated in BilkaKaufhaus, the discriminatory measure must correspond to a "real need" in order to be deemed a legitimate aim. ${ }^{235}$

Even if a legitimate aim is pursued, the measure taken must still be deemed necessary and proportionate. As was demonstrated in $C H E Z$ in relation to the offensive nature of the meter installation in an unreachable height, if advertisement practices closely overlap with, for example, stereotypical grouping, they could be seen as offensive and stigmatizing. ${ }^{236}$ In such a case, certain ads could potentially be unlawful even if a legitimate aim is pursued and no less-infringing measures exist. ${ }^{237}$ The stigmatizing nature of the practice, specifically showing certain ads to certain groups, could make this practice disproportionate and therefore potentially illegal. And as mentioned above, if these ads are seen as illegal, they would not only violate directly or indirectly the interests of people that share the protected attribute, but also violate the interests of people that were associated with this group on the basis of discrimination by association.

Of course, a claim will only be successful if the advertisements in question fall under one of the protected areas (e.g., employment), affects legally protected groups (e.g., religion or beliefs), and a particular disadvantage occurred. Moreover, finding a comparable group that is treated significantly better can be difficult due to opaque algorithmic behavior and business models, as well as the dispersed nature of advertisement provisioning, which can increase the difficulty of locating other relevant individuals who were or were not shown a particular advertisement.

233. Id.

234. See supra note 14.

235. Case C-170/84, 1986 E.C.R. 1620, supra note 212, at 9甲 36-37.

236. CHEZ, Advisory Opinion, supra note 168, at 9 甲 60, 84, 87, 108, 128.

237. Id. at 128.; Grozev, supra note 170, at 183. 


\section{PROTECTION OF NON-TRADITIONAL GROUPS}

Even if these hurdles are overcome, and even with the most generous interpretations of non-discrimination and data protection law, these frameworks could still fail to guard against the novel risks of inferential analytics. Discriminatory advertising practices can equally affect new types of groups created through inferential analytics that do not map onto historically protected attributes. Both types of law might fall short in providing adequate protection to groups that fall outside the scope of legally protected groups.

Automated decision-making and profiling expand the range of potential victims of discrimination and other potential harms (e.g., privacy, financial, and reputational) beyond traditionally protected groups. Profiling seeks to identify unintuitive connections between people and to group or otherwise stratify them according to attributes that do not count as special category data or fall within the remit of non-discrimination law. In practice, profiling constructs ephemeral groups of potentially similar individuals. ${ }^{238}$ This type of classification can prove problematic in two ways: either by drawing invasive inferences from a dataset, which is a problem of privacy and data protection, or by taking unacceptable actions based on these inferences, which is a problem of discrimination. ${ }^{239}$ European data protection and nondiscrimination law may not sufficiently guard against these risks.

Data protection law only applies to drawing inferences if personal data is processed and the data relates to an identifiable individual. ${ }^{240}$ Inferencedrawing practices can thus avoid data protection law in a few ways. Group profiling can be done by evaluating data about other people or data that does not fall under data protection law (e.g., non-personal data or anonymized data). ${ }^{241}$ While individuals have no control or protections against insights drawn from these types of data, the data can nonetheless reveal intimate details of the individual's life.

Profiling can also be performed without singling out data subjects. ${ }^{242}$ But identifying and singling out individuals is a precondition for data protection

238. Brent Mittelstadt, From Individual to Group Privacy in Big Data Analytics, 30 PHIL. \& TECH. 475, 478 (2017).

239. See supra Section II.C, Part III.

240. See GDPR, supra note 61, at art. 4(1) (“' ‘P]ersonal data' means any information relating to an identified or identifiable natural person ('data subject'); an identifiable natural person is one who can be identified, directly or indirectly, in particular by reference to an identifier such as a name, an identification number, location data, an online identifier or to one or more factors specific to the physical, physiological, genetic, mental, economic, cultural or social identity of that natural person ....”).

241. See Wachter, supra note 21 , at 7.

242. See Mittelstadt, supra note 23, at 478. 
law to apply. According to the Working Party, a person is singled-out or "considered as 'identified' when, within a group of persons, he or she is 'distinguished' from all other members of the group." ${ }^{243}$ Successful affinity profiling does not require identifying or singling out data subjects in this sense, but nonetheless allows for sensitive information to be inferred which can drive discriminatory actions. This observation suggests that, in order to sufficiently protect against the novel risks and new types of groups created by profiling and inferential analytics, it would be sensible to abandon artificial data categories and no longer focus solely on identifiability, and instead create new protections based on holistic notions of data about people and group conceptions of privacy. ${ }^{244}$

With regard to actions based on inferences made, similar problems arise with European non-discrimination law, which is based on historical lessons. Non-discrimination laws protect, for example, against religion and genderbased direct and indirect discrimination because such discrimination has occurred in the past. ${ }^{245}$ However, inferential analytics can identify new patterns and similarities between individuals, ${ }^{246}$ who can then be grouped for purposes of ad provisioning. The difficulty is that these new type of "ad hoc groups" are not guaranteed to align or correlate with the traditional social constructs or attributes (e.g., religion, gender, or ethnicity) protected in non-discrimination law, and yet these groups will experience discrimination with comparable harmful effects via the same mechanisms as protected groups. ${ }^{248}$

Inferential analytics widens the range of victims of discriminatory actions. These new types of victims do not map to or might not correlate with current concepts in the law, as new types of discrimination become possible. For

243. Even though knowing the name is not necessary to be singled out, other identifiers (e.g., "socio-economic, psychological, philosophical or other criteria") might suffice. See Article 29 Data Prot. Working Party, Opinion 4/2007 on the Concept of Personal Data, 01248/07/EN WP 136, at 12-13 (adopted June 20, 2007) [hereinafter Art. 29 WP Op. 4/2007].

244. Wachter, supra note 21, at 7; Tal Z. Zarsky, Incompatible: The GDPR in the Age of Big Data, 47 SETON HALl L. REv. 995, 1013 (2017) (addressing the need to redefine artificial data categories).

245. Mantelero, supra note 22, at 765; see generally Alessandro Mantelero, Personal Data for Decisional Purposes in the Age of Analytics: From an Individual to a Collective Dimension of Data Protection, 32 COMPUT. L. \& SEC. REV. 238 (2016). For an analysis of discrimination under U.S. law, see generally Solon Barocas \& Andrew D. Selbst, Big Data's Disparate Impact, 104 CALIF. L. Rev. 671 (2016).

246. Samuel Yeom, Irene Giacomelli, Matt Fredrikson \& Somesh Jha, Privacy Risk in Machine Learning: Analyzing the Connection to Overfitting, in 2018 IEEE 31ST COMPUT. SEC. FOUND. SYMP. 268, 268-69 (2018).

247. Mittelstadt, supra note 23, at 485.

248. Mantelero, Personal Data, supra note 245, at 240. 
example, less favorable treatment can be given for people who own dogs, ${ }^{249}$ are born on a Tuesday, are identified as "sad teens,"250 "Young Single Parents," ${ }^{251}$ or video gamers, ${ }^{252}$ or people who belong to groups that occupy legal or ethical grey areas such as gamblers, ${ }^{253}$ or drug addicts. Even more opaque are groups that are created by neural nets where we have no concept in our language to describe the characteristics of the group or the inferences drawn about the group. ${ }^{254}$ In other words, groups of individuals perceived to be similar to one another can be unfairly treated (e.g., offered high-cost loans and financially risky products), ${ }^{255}$ without being singled out on the basis of sensitive attributes. ${ }^{256}$

Put differently, groups such as "dog owners" are not protected under nondiscrimination law. As a result, no protection under direct discrimination is possible. Of course, claims can be made under indirect discrimination if dog ownership correlates with a protected attribute and all the other conditions mentioned in Part IV are met. Apart from the technical difficulties ${ }^{257}$ to detect the proxy power of dog ownership, it might be the case that this category does not sufficiently correlate with a protected group, where disproportionately affected means around $80-90 \%$ of the group are disadvantaged. ${ }^{258}$ The ECJ

249. For an overview of commonly used interest categories (including "Winter Activity Enthusiast," “dog owner," and "Heavy Facebook User”), see generally FED. TRADE COMM'N, Data Brokers: A CALl FOR TRANSPARENCY AND ACCOUNTABILITY B-2-B-6 (2014).

250. Michael Reilly, Is Facebook Targeting Ads at Sad Teens?, MIT TECH. REV., https:// www.technologyreview.com/s/604307/is-facebook-targeting-ads-at-sad-teens/ (last visited Apr. 19, 2019).

251. Art. 29 WP Feb. Guidelines, supra note 6, at 10.

252. Being labelled as a video gamer can cause the Chinese Social Credit Score to drop. See Nicole Kobie, The Complicated Truth About China's Social Credit System, WIRED UK June 7, 2019, https://www.wired.co.uk/article/china-social-credit-system-explained.

253. The Working Party warns about the possible exploitation of gamers via nudging and online ads. See Article 29 Data Protection Working Party, Guidelines on Automated individual decision-making and Profiling for the purposes of Regulation 2016/679, 17/EN WP 25111 (2017), http://www.hldataprotection.com/files/2017/10/20171013_wp251_enpdf.pdf (last visited Oct 22, 2017).

254. Jason Yosinski, Jeff Clune, Anh Nguyen, Thomas Fuchs \& Hod Lipson, Understanding Neural Networks Through Deep Visualization, (June 22, 2015) (unpublished manuscript) https://arxiv.org/abs/1506.06579 (regarding visualizations of the intermediate layers of neural networks to make the network's computations more comprehensible).

255. Art. 29 WP Feb. Guidelines, supra note 6, at 18.

256. See Mittelstadt, supra note 23, at 478 (regarding how algorithmic groups are assembled which are not reducible to individual data subjects or their privacy interests and the regulatory gap for these groups caused by the focus in data protection law on identifiable individuals).

257. On the challenge to detect proxy data, see Kusner et al., supra note 58 (discussing the challenges of causal and counterfactual reasoning in detecting algorithmic bias).

258. See supra Section IV.B.2. 
ruled that it is not within its power to create new protected groups (e.g., "dog owners") as the list in the Directives is exclusive. ${ }^{259}$ Similarly, in relation to the proportionality threshold, the court explained that a measure must, "taken in isolation," 260 produce the disproportionate effect for one of the protected grounds. It might be the case that the profile of "dog owners" is not homogenous enough to meet this requirement. Nonetheless, it can still seem unreasonable, counterintuitive, or unjust to use dog ownership as a deciding factor for loan applications, despite it being lawful to use the characteristic as a basis for decision-making.

These new types of groups also face new challenges in terms of organization and collective action. Members of ad hoc groups often do not know that they are part of the group. They are thus less able than historically protected groups to protect themselves against new forms of discrimination and other harms made possible by inferential analytics. ${ }^{261}$ A clear collective interest for new forms of group protection is evident, even if specific ad hoc groups cannot themselves advocate for it. ${ }^{262}$ Reflecting this, scholars across law and ethics are beginning to call for greater protection of group interests. ${ }^{263}$

Mireille Hildebrandt, for example, explains that "we have no access to the group profiles that have been inferred from the mass of data that is being aggregated and have not the faintest idea how these profiles impact our

259. Coleman, supra note 15 , at 46.

260. The case was centered around a case of intersectionality where the claimant sued on the basis of the combined factors "age" and "sexual orientation," where one measure in isolation did not produce a discriminatory effect. Case C-443/15, Parris v. Trinity College Dublin, ECLI:EU:C:2016:897, $\mid 80$ (Nov. 24, 2016). This shows that one protected group needs to meet the threshold of disproportionality. For a strong critique, see Howard, supra note 166, at 69. For an in-depth discussion of this case and on problems with intersectionality in general, see generally Dagmar Schiek, On Uses, Mis-Uses and Non-Uses of Intersectionality Before the European Court of Justice (ECJ), 7 CETLS ONLINE PAPER SERIES 1 (2018).

261. Mittelstadt, supra note 23, at 485.

262. Mantelero, Personal Data, supra note 245, at 245.

263. See Mittelstadt, supra note 23; see generally Group PrivaCy: New Challenges of Data Technologies (Linnet Taylor, Luciano Floridi, \& Bart van der Sloot eds., 1st ed. 2017); Mantelero, Personal Data, supra note 245; Lee A. Bygrave, Data Protection Law: Approaching Its RATIONALE, LogiC AND Limits (2002). On why big data is challenging for privacy protection, see generally Solon Barocas \& Helen Nissenbaum, Big Data's End Run Around Procedural Privacy Protections, 57 COMM. ACM 31 (2014). 
chances in life." ${ }^{264}$ In part this is due to group profiles often being protected as trade secrets. ${ }^{265}$

Lee A. Bygrave (as one of the first), ${ }^{266}$ Linnet Taylor et al., ${ }^{267}$ and Alessandro Mantelero ${ }^{268}$ have made similar calls explaining that data protection law is not equipped for this challenge. Mantelero, for example, calls for collective privacy rights for affected parties. ${ }^{269}$ To enforce this, he suggests that a third party could represent the interests of the group and an independent party could conduct impact assessments prior to processing in order to prevent large-scale discrimination and harms. ${ }^{270}$

The risks of automated decision-making and profiling for groups have also been acknowledged by the Working Party. ${ }^{271}$ Their guidelines on automated decision-making state that "[p]rocessing that might have little impact on individuals generally may in fact have a significant effect on certain groups of society, such as minority groups or vulnerable adults." ${ }^{272}$ It remains open whether "groups" in this context refers only to traditional vulnerable groups (e.g., children) or also to groups assembled in a non-traditional sense. The broader interpretation seems likely, as the guidelines also state that "[i]ndividuals may wish to challenge the accuracy of the data used and any grouping or category that has been applied to them," ${ }^{273}$ which is not explicitly limited to traditionally protected groups or attributes.

It is not unrealistic to assume that ad hoc group privacy interests will be enshrined in law in the future considering the Working Party's stance. The

264. Mireille Hildebrandt, Profiling and the Rule of Law, 1 IDENTITY INFO. SOC’Y 55, 64 (2009), https:// papers.ssrn.com/abstract=1332076.

265. Mireille Hildebrandt, Smart Technologies and the End(s) of Law: Novel Entanglements of LaW And Technology 93, 103, 139, 222 (2015); see also Hildebrandt, Profiling and the Rule of Law, supra note 264, at 63-65.

266. See generally BYgrave, supra note 263; Lee A. Bygrave, Privacy Protection in a Global Context - A Comparative Overview, 47 Scandinavian. Stud. L. 319 (2004).

267. See generally Group Privacy: New Challenges of Data Technologies, supra note 263.

268. See generally Mantelero, Personal Data, supra note 245 (regarding the absence of collective dimensions in data protection law); Alessandro Mantelero, From Group Privacy to Collective Privacy: Towards a New Dimension of Privacy and Data Protection in the Big Data Era, in GROUP PRIVACY 139 (2017) (regarding the recognition of group privacy in data protection law); Alessandro Mantelero \& Giuseppe Vaciago, Data Protection in a Big Data Society. Ideas for a Future Regulation, 15 DigitAl InveSTIGATION 104 (2015) (regarding the challenges for data protection law introduced by Big Data).

269. Mantelero, Personal Data, supra note 245, at 249-250.

270. Id. at 250 .

271. See generally Art. 29 WP Feb. Guidelines, supra note 6.

272. Id. at 11.

273. Id. at 24 . 
Working Party takes issue with profiling which could deprive individuals of "opportunities based on the actions of others" 274 by using "non-traditional credit criteria, such as an analysis of other customers living in the same area who shop at the same stores, ${ }^{275}$ without having remedies against it. Following this, the guidelines recommend that the data subject is "given information about their profile, for example in which 'segments' or 'categories' they are placed." ${ }^{276}$ Further, the Working Party suggested that the "conclusive list of data being regarded as sensitive per se - could be amended so as to react more flexibly to possible new forms of sensitive data or new forms of data and data processing which could lead to severe infringements of privacy."277

\section{SOLUTIONS FOR ACCOUNTABILITY IN OBA AND AFFINITY PROFILING}

With the shortfalls in data protection and non-discrimination law now clear, there are several potential solutions to address legal challenges facing OBA and affinity profiling.

\section{A. A Right TO REASONABLE INFERENCES IN OBA}

Inferential analytics expose accountability gaps in both privacy protection and non-discrimination law. Data protection law does not offer sufficient protection against sensitive inferences, inferences based on non-personal or anonymized data, or profiling that does not single out individuals. Similarly, non-discrimination law only offers protection for traditional groups in specific sectors and only if the group is disproportionately affected, and thus ignores new types of algorithmic or profiling groups (e.g., "dog owners" or groups defined by incomprehensible characteristics).

Recognizing these novel risks of big data, AI, and inferential analytics, a "right to reasonable inferences" could close the current gaps in data protection and non-discrimination law. ${ }^{278}$ Rather than playing catch-up and adding new types of sensitive data or protected groups to existing laws, a holistic and sectoral approach is more promising.

274. Id. at 12; see also Kaveh Waddell, How Algorithms Can Bring Down Minorities' Credit Scores, ATLANTIC (Dec. 2, 2016), https://www.theatlantic.com/technology/archive/2016/12/how -algorithms-can-bring-down-minorities-credit-scores/509333/[https://perma.cc/S5Z2 -MUZP].

275. Art. 29 WP Feb. Guidelines, supra note 6, at 22.

276. Id. at 23 .

277. Art. 29 WP Advice Paper, supra note 62, at 3.

278. See generally Wachter \& Mittelstadt, supra note 39. 
A right to reasonable inferences would address the harms of "high risk inferences," which (1) are privacy-invasive or damaging to reputation, or have a high likelihood of being so in the future, or (2) have low verifiability in the sense of being predictive or opinion-based and are used for important decisions (e.g., loans and jobs). ${ }^{279}$ The first condition effectively sets a proportionality test, according to which the privacy invasion or reputational damage posed by using a particular data source to draw an inference must be proportional to the predicted benefit or utility. This right would govern:

(1) why certain data form a normatively acceptable basis from which to draw inferences; (2) why these inferences are relevant and normatively acceptable for the chosen processing purpose or type of automated decision; and (3) whether the data and methods used to draw the inferences are accurate and statistically reliable. ${ }^{280}$

In addition to these ex-ante mechanisms that provide context and justification for inferences drawn, the right would require "an additional expost mechanism enabling unreasonable inferences to be challenged." ${ }^{281}$ For example, data controllers could enable data subjects to submit additional information so they might reconsider or rectify decisions or assessments.

If such a right was granted, the new protections offered would extend further than mere protection against discrimination, privacy invasion, and opaque algorithmic measures. This would allow for more agility on a sectoral basis. The right demands justification of new high-risk forms of inferential analytics. It would, for example, protect individuals against being grouped according to inferred "unethical" attributes (e.g., gambling addiction or mental vulnerability) and guarantee that inferences drawn are accurate (e.g., that individuals have at a minimum been grouped accurately or with reliable statistical measures). The right aims to protect against high-risk unreasonable inferences and important or high-impact decisions based on them, which could include discriminatory OBA and affinity profiling. This right could potentially provide a remedy if designed to detect both individual and group level harms or to notify individuals as groups are formed and used in profiling or decision-making, which could facilitate contestation of group membership.

279. Id. at 619 .

280. Id. at 495. The types of data used to draw inferences could include, for example, browsing history, geolocation, or clicks and 'likes' on social media. Types of automated decisions could include inferring sexual orientation or political views to display advertisements. The accuracy and statistical reliability of data concerns could be improved through testing and verification for bias in the data that underlies inferences and automated decisions.

281. Id. at 588 . 


\section{B. CurRent GOVERnANCE Strategies}

Another key question to improve the accountability of OBA and affinity profiling concerns whether current governance strategies used by policymakers and companies are fit for the purpose of protecting against discriminatory OBA and affinity profiling. Progress has been made in recent years both by the public sector and the private sector, but it is still not enough.

The Working Party commented on the potential privacy implication of tracking cookies and geolocation data for advertising. ${ }^{282}$ Their guidelines explain that "given the sensitivity of such information and the possible awkward situations which may arise if individuals receive advertising that reveals, for example, sexual preferences or political activity, offering/using interest categories that would reveal sensitive data should be discouraged." 283

The Working Party also proposed greater transparency as a remedy to the general privacy challenges of cookies and geolocation data. Specifically, they argued that providing data subjects and consumers with immediate information about data processing in relation to OBA can help transform informed and explicit consent into effective accountability mechanisms. ${ }^{284}$

While this is a good idea in theory, it overlooks the fact that it has been long recognized that consent is not a suitable governance mechanism for data protection. ${ }^{285}$ In the context of OBA, the ubiquity of advertisements and the underlying data analytics used to create audiences and target advertisements suggests well-informed consent is particularly difficult. Consent also fails to address the justification of data uses ${ }^{286}$ (e.g., whether the proposed processing is ethically acceptable independent of whether consent has been given) and how data controllers handle a data subject's refusal to give consent or object to processing. ${ }^{287}$

282. Art. 29 WP Feb. Guidelines, supra note 6.

283. Art. 29 Data Prot. Working Party, Opinion 2/2010, supra note 80, at 19.

284. Id. at 24-26.

285. For strong critics of the functionality of informed consent, see, for example, Daniel J. Solove, Privacy Self-Management and the Consent Dilemma, 126 HARV. L. REV. 1880 (2013); Paul M. Schwartz, Internet Privacy and the State, 32 ConN. L. REV. 815 (1999); Zuiderveen Borgesius, supra note 35, at 251-255; N. Van Eijk, N. Helberger, L. Kool, A. van der Plas \& B. van der Sloot, Online Tracking: Questioning the Power of Informed Consent, 14 INFO 57 (2012); Bert-Jaap Koops, The Trouble with European Data Protection Law, 4 INT'L. DATA PRIVACY L. 250 (2014); Smit, Van Noort \& Voorveld, supra note 2, at 20 (regarding knowledge as a prerequisite for informed consent which is often lacking in online interactions).

286. Wachter \& Mittelstadt, supra note 39, at 581-88.

287. However, the situation might improve in the future as "forced consent" is no longer possible under Article 7 of the GDPR; complaints against Google and Facebook in this vein have already been launched. See Max Schrems, GDPR: noyb.eu Filed Four Complaints over "Forced Consent" Against Google, Instagram, WhatsApp and Facebook (May 25, 2018), https:// 
To address the difficulty that the ubiquity of OBA creates for consent, insofar as individuals would experience information overload if given detailed information about every advertisement encountered, the Working Party suggested using icons and explanations to help users understand why they have been served with certain ads. ${ }^{288}$ Companies such as Google and Facebook are currently offering explanations as to why certain ads have been shown to their users. ${ }^{289}$

These explanations generally reveal the interest groups in which users have been placed. Google informs with "Why you're seeing an ad" and "why this ad" explanations. ${ }^{290}$ In their Ad Settings, Google also provides information about the inferences on which ads are served, including, for example, age, education, an interest in fitness, or an interest in video games. ${ }^{291}$ Facebook also provides generic explanations in their "Why Am I Seeing This" feature, which generally addresses the influence of age, geolocation, profile information, and previously visited sites on displayed advertisements. ${ }^{292}$

While current industry standards are an encouraging first step, they remain insufficient for at least two reasons. First, users often do not see or do not understand the explanations provided. Boerman et al. assessed users' attitudes and perception towards OBA and transparency and found that users rarely notice disclosures such as icons, logos, or other transparency banners, such as the "Why did I get this ad?" or "AdChoices" features. Even when noticed, users often do not understand the icons or the labels provided. ${ }^{293}$

Second, the explanations provided are often too generic or vague and provide little detail specific to the individual. If explanations are intended to

www.stetson.edu/law/studyabroad/spain/media/Wk3.Stuart.Day3-2-Forced-Consent -Complaints.pdf.

288. Art. 29 WP Feb. Guidelines, supra note 6, at 18.

289. Ad SetTings, GoOgLe, https://perma.cc/8J6G-VYPD (last visited Apr. 20, 2020); Why am I seeing ads from an advertiser on Facebook?, FACEBOOK, https:// www.facebook.com/help/794535777607370?helpref=popular_topics (last visited Apr. 20, 2020).

290. Ad SETTINGs, GOOGLE, supra note 289.

291. Users can opt-out of personalized advertisements, but generic ads are still shown.

292. Why am I seeing ads from an advertiser on Facebook?, supra note 289. On why this transparency tool is not sufficient, see Athanasios Andreou, Giridhari Venkatadri, Oana Goga, Krishna P. Gummadi, Patrick Loiseau \& Alan Mislove, Investigating Ad Transparency Mechanisms in Social Media: A Case Study of Facebook's Explanations, in NETWORK \& DisTRIBUTED SYS. SEC. SYMP. 20181 (2018), https://www.ndss-symposium.org/wp-content/uploads/2018/02 /ndss2018_10-1_Andreou_paper.pdf.

293. Boerman, Kruikemeier \& Zuiderveen Borgesius, supra note 2, at 367; Pedro Giovanni Leon, Justin Cranshaw, Lorrie Faith Cranor, Jim Graves, Manoj Hastak, Blase Ur \& Guzi Xu, What Do Online Behavioral Advertising Privacy Disclosures Communicate to Users?, in PROC. 2012 ACM WORKSHOP ON PRIV. ELEC. SOC’Y 19, 12 (2012). 
increase transparency and accountability in OBA, they must provide information necessary for users to assess whether their privacy has been respected, as well as whether discrimination has occurred, for instance, due to sensitive information being illegally used or inferred.

NGOs and activist groups routinely criticize current industry standards and practices along these lines. Numerous complaints have recently been submitted pushing for greater clarity on the legal and ethical acceptability of inferential analytics in OBA. ${ }^{294}$

The path forward to prevent harmful and illegal OBA must center on algorithmic accountability. A transparent business approach can also be beneficial for the business interests of companies. Users value transparency ${ }^{295}$ and feel vulnerable if they see ads that are based on previous online activities. ${ }^{296}$ Following this, Guda Van Noort et al. suggest informing users immediately that an ad has been shown because of their surfing behavior. ${ }^{297}$ Research shows that users do not want to be tracked and find OBA to be privacy invasive. ${ }^{298}$ Prior research found that "highly personalized advertisements" decreased

294. See, e.g., Privacy International Files Complaints Against Seven Companies for Wide-Scale and Systematic Infringements of Data Protection Law, PRIV. INT'L, https://privacyinternational.org /press-release/2424/privacy-international-files-complaints-against-seven-companies-wide -scale-and (last visited Mar. 4, 2019); Our Complaints Against Acxiom, Criteo, Equifax, Experian, Oracle, Quantcast, Tapad, PRIV. INT'L, https://privacyinternational.org/advocacy-briefing /2426/our-complaints-against-acxiom-criteo-equifax-experian-oracle-quantcast-tapad (last visited Mar. 4, 2019); Johnny Ryan, Regulatory Complaint Concerning Massive, Web-Wide Data Breach by Google and Other "Ad Tech" Companies Under Europe's GDPR, BRAVE Browser (2018), https://www.brave.com/blog/adtech-data-breach-complaint/ (last visited Mar. 4, 2019); PI Joins Open Letter to Facebook Regarding Ads Transparency, PRIV. INT'L, https:/ / privacyinternational .org/advocacy-briefing/2734/pi-joins-open-letter-facebook-regarding-ads-transparency (last visited May 11, 2019); Why Am I Seeing This on Facebook? It's Still Unclear, PRIV. INT'L, https://web.archive.org/web/20190531171839/https://privacyinternational.org/news/277 2/why-am-i-seeing-facebook-its-still-unclear (last visited May 11, 2019); Update report into adtech and real time bidding, 20 June 2019, INFO. COMM’N'S OFF. 31, https://ico.org.uk/media /about-the-ico/documents/2615156/adtech-real-time-bidding-report-201906.pdf (last visited Apr. 20, 2020) (stating that real time bidding is incompatible with the GDPR).

295. Chris Jay Hoofnagle, Jennifer M. Urban \& Su Li, Privacy and Modern Advertising: Most US Internet Users Want "Do Not Track" to Stop Collection of Data About Their Online Activities, in Amsterdam PRIV. CONF. 2012, 1, 11-12 (2012); Boerman, Kruikemeier \& Zuiderveen Borgesius, supra note 2, at 367.

296. Elizabeth Aguirre, Dominik Mahr, Dhruv Grewal, Ko de Ruyter \& Martin Wetzels, Unraveling the Personalization Paradox: The Effect of Information Collection and Trust-Building Strategies on Online Advertisement Effectiveness, 91 J. RETAILING 34, 34 (2015).

297. Guda Van Noort, Edith G. Smit \& Hilde AM Voorveld, The Online Behavioural Advertising Icon: Two User Studies, 4 ADVANCES ADVERT. REs. 365, 366 (2013).

298. See Smit, Van Noort \& Voorveld, supra note 2, at 16; Boerman, Kruikemeier \& Zuiderveen Borgesius, supra note 2 , at 372. 
clickthrough rates ${ }^{299}$ while greater transparency had the opposite effect. ${ }^{300}$ More transparent business models in OBA can therefore benefit users, platform providers, and advertisers, simultaneously.

\section{Open PROBLEMS}

As shown in this Article, OBA raises at least three areas of concern where the law might be insufficient: privacy, non-discrimination, and group privacy protection. Part II demonstrated how the concept of affinity profiling is deployed; grouping people according to their assumed interests rather than solely on their personal traits (e.g., ethnicity or sexual orientation). It also discussed the court's and scholars' views on the need to meet the threshold of intentionality and reliability to turn personal data into sensitive data. Finally, it also showed how this threshold might render Article 9 of the GDPR inapplicable. Part III examined the scope of E.U. non-discrimination law and discussed its problematic limitations in terms of the areas to which it applies (i.e., only employment, welfare, and goods and services including housing) and the people it protects (i.e., lawful discrimination based on gender in media and advertisements, and protection against discrimination based on religion, disability, age and sexual orientation only in relation to employment).

Then, Part IV proposed the concept of discrimination by association to challenge the idea that assumed interests and personal traits are strictly unrelated, which potentially could render regulation inapplicable. Discrimination by association establishes a basis for more effective protection against discriminatory OBA by providing a possible path to close some of the current accountability gaps in affinity profiling, regardless of whether the practice is considered to use explicitly protected traits or accepted proxies.

In assessing the utility of discrimination by association as a legal concept, the first question to address is whether affinity profiling should be seen as a direct use of protected traits because of its close connection or strong correlation between affinity profiles and those protected traits. If this question is answered in the affirmative, affinity profiling may constitute direct discrimination. However, arguing that only an affinity with the protected category, for example ethnicity, is assumed but no actual ethnicity is inferred could render regulation inapplicable.

299. Aguirre et al., supra note 296, at 34-37; see also Boerman, Kruikemeier \& Zuiderveen Borgesius, supra note 2, at 365; see generally Frederik J. Zuiderveen Borgesius, Sanne Kruikemeier, Sophie C. Boerman \& Natali Helberger, Tracking Walls, Take-It-Or-Leave-It Choices, the GDPR, and the ePrivacy Regulation, 3 Eur. DATA Prot. L. REv. 353 (2017) (providing empirical evidence that customers reject highly personalized advertisements).

300. Boerman, Kruikemeier \& Zuiderveen Borgesius, supra note 2, at 369. 
This gap can be closed by using the concept of discrimination by association. As illustrated in Coleman, discrimination by association allows individuals to bring a claim if they suffer discriminatory negative effects from a measure taken against a protected group, even if they are not a member of that protected group. Discrimination by association grants protection if someone is treated significantly worse based on their relationship or association (e.g., affinity for African-American culture) with a group that possesses a protected attribute. As a result, it would not matter whether the person is part of the protected group or if the taken measure is based on a protected attribute they actually possess. Due to the strong correlation and disclosive power of one's interests and one's sensitive traits (e.g., affinity for African-American culture and being African-American), this concept could grant more protection against undesired and unlawful discrimination based on interests or, by extension or proxy, on sensitive traits.

Discrimination by association is a powerful tool to close some of the current accountability gaps in OBA. People who do not possess protected traits (e.g., misclassified users) can bring a claim, which can help combat discrimination on a larger scale. Widening the circle of potential claimants could also strengthen the relationship between allies of civil rights movements (e.g., LGBTQ+, religious, women's). Moreover, not granting protection to misclassified users could have an undesirable chilling effect due to fear of potential negative consequences based on associating with these groups.

Following this logic, members of the group also should not need to prove that they are a member of this group. This can help combat potential public stigmatization based on protected attributes. Intent does not need to be proven on the side of the alleged offender and no concrete victim needs to be identified, meaning the discriminatory practice does not need to be effective to be considered discriminatory (e.g., preventing women from applying for jobs) for prima facie discrimination. Of course, claims of discrimination will only be successful if they can show that there was no justification for differential treatment. However, only a very limited number of cases will be justified because direct discrimination is only lawful if a legitimate basis exists in a non-discrimination directive or Member State law.

If affinity profiling is ultimately seen as not involving direct usage of protected traits because the interest groups are seen as sufficiently distinct from protected categories such as "race" and "ethnicity" as described in the Directives, claims based on direct discrimination could not be made. However, under these conditions, affinity profiling could still constitute indirect discrimination or indirect discrimination by association if this practice disproportionately negatively affects a protected group in comparison to 
others in a similar situation. Thus, if this practice disproportionately adversely affects a protected group, it could be illegal (e.g., differential pricing or complete exclusion from certain ads), unless there is a justification for the adverse action. Here, again, the concept of discrimination by association would allow people who are not part of this group to bring a claim, while people who are part of the group would not need to "out" themselves. And again, the claimant does not need to establish the offender's intent. The law might therefore already have a solution to advertising based on correlations of user interests that leads to discriminatory differential results.

In CHEZ, the ECJ also left open the question of whether or not the meter installations in an unreachable height constitutes direct or indirect discrimination by association. ${ }^{301}$ This means that the boundaries between actions and practices that constitute direct or indirect discrimination are fluid. The decision to show certain ads based on assumed affinities could fall under either category with almost no legal justification for the former.

Nonetheless, claimants may face difficulties proving that discrimination occurred. To prove indirect discrimination, the claimant would need to find a comparison group that is treated favorably, and then show that, in comparison with others, a sufficiently large proportion of a protected group was subject to a particular disadvantage (i.e., does the ephemeral nature of OBA make it less harmful?). Unfortunately, as shown in Section IV.B.1, standards of what constitutes a particular disadvantage are not coherent in E.U. case law, although the ECJ has clarified that the threshold should not be set too high because the explicit goal of the directives is to combat illegal discrimination. ${ }^{302}$ This means an indication of less favorable treatment in advertising could be seen in differential pricing or exclusion from goods and services for certain groups. Finally, the claimant would need to show that the particular disadvantage affected the protected group in a disproportionately negative way when compared with others in a similar situation. Unfortunately, the jurisprudence, as shown in Section IV.B.2, is somewhat inconsistent and does not provide a clear threshold of legally acceptable disparity (e.g., must affect a "far greater number of women" 303 ), usually $80-90 \%$. It remains open whether this threshold is socially acceptable.

Other practical and procedural challenges remain. More algorithmic transparency is urgently needed. As mentioned above, to be successful, the claimant will need to show that the "apparently neutral provision, criterion or

301. CHEZ, supra note 16, at 9 129(4).

302. See supra Section IV.B.1.

303. Eur. Union AGENCY FOR FundAMENTAL Rights \& COUNCIL OF EuR., supra note 98, at 242-43. 
practice" ${ }^{304}$ caused a particular disadvantage and affected a protected group disproportionately negatively when compared with others. The lack of transparency in algorithmic decision-making and business practices in OBA will make this a difficult task. In the same vein lies the difficulty of identifying other members of a targeted audience, which is crucial because the claimant will also need to prove that the differential results affected the protected group disproportionately and identify a comparator that received more favorable treatment. Not knowing the rules, assumed interests, or attributes on which one is profiled, and whether these assumed interests correlate with protected attributes (i.e., not knowing if the interest group correlates with protected traits and to what extent $)^{305}$ adds further complexity to this task.

Thankfully, there is a vivid field of research dedicated to bias and fairness in machine learning that helps to shed light on proxy data and the extent to which it affects certain groups. ${ }^{306}$ The importance of this research field cannot be overstated: it can help establish prima facie discrimination (e.g., post codes and the subsequent regulation/ban of redlining), ${ }^{307}$ which is sufficient to shift the burden of proof from claimants to the accused.

As shown in Section IV.C, alleged offenders can still show that indirect discrimination was justified by establishing a legitimate aim, necessity, and proportionality. However, purely economic reasons alone are unlikely to qualify as a legitimate aim to justify a discriminatory (business) practice. Moreover, even if a legitimate aim was pursued and the means were necessary, the proportionality test could still fail if a practice is seen as "offensive or stigmatising" and therefore deemed disproportionate. ${ }^{308}$

304. Supra note 14.

305. On the challenge to detect proxy data, see generally Kusner et al., supra note 58 . On legal and technical challenges, see generally Indré Žliobaite, Measuring Discrimination in Algorithmic Decision Making, 31 Data Mining \& KNOwledge Discovery 1060 (2017). On the need to collect sensitive data to avoid discrimination, see generally Ignacio N. Cofone, Algorithmic Discrimination Is an Information Problem, 70 HASTINGS L.J. 1389 (2019).

306. To name a few see Kusner et al., supra note 60; Russell et al., supra note 60; Dwork et al., supra note 60; Friedler, Scheidegger, and Venkatasubramanian, supra note 60; GrgicHlaca et al., supra note 60; Celis, Mehrotra, and Vishnoi, supra note 47; Speicher et al., supra note 57.; Meike Zehlike, Philipp Hacker \& Emil Wiedemann, Matching code and law: achieving algorithmic fairness with optimal transport, 34 DATA MinING \& KNOWLEDGE DisCOVERY 163 (2020).

307. For examples in Germany see Wachter and Mittelstadt, supra note 25 at at 587.; for examples from the United States, see generally Willy E. Rice, Race, Gender, Redlining, and the Discriminatory Access to Loans, Credit, and Insurance: An Historical and Empirical Analysis of Consumers Who Sued Lenders and Insurers in Federal and State Courts, 1950-1995, 33 SAN DiEGO L. REV. 583 (1996).

308. CHEZ, supra note 16, at $\$ 128$. 
Moreover, Part V and Section VI.A showed that there is a clear need to afford greater protection to the privacy interests of the groups formed by modern inferential analytics and targeted by OBA. The challenge is that the analytics behind many automated decision-making and profiling is not concerned with singling out or identifying a unique individual, but rather with drawing inferences from large datasets, calculating probabilities, and learning about types or groups of people. ${ }^{309}$ Third-party, anonymized, or non-personal data can be used for these purposes. Unfortunately, data protection law only applies to the personal data of identifiable individuals. Therefore, new legal mechanisms based on group or collective privacy interests may be necessary to close the accountability gap created by data-driven OBA at scale. ${ }^{310}$ Profiling and inferential analytics expand the circle of victims to include groups that may not qualify for protection under non-discrimination because they do not map on to traditional social concepts of protected traits (e.g., "sad teens" 311 or video gamers). ${ }^{312}$

Finally, current public and private sector governance tools discussed in Sections VI.B and VI.C are welcome and encouraged, but leave much to be desired. Platform providers currently offer generic and vague explanations of why certain advertisements have been served. These types of explanations do not alleviate the aforementioned concerns. Without greater algorithmic and business transparency in OBA, it will remain very difficult for individuals, regulators, or NGOs to prove that one of privacy violations, differential treatments, or differential results have occurred.

However, explanations of how advertisements are served based upon assumed interests and sensitive characteristics can, if well formulated, provide an effective tool to contest discriminatory advertisements, and thus increase accountability in algorithmic profiling and decision-making.

\section{POLICY RECOMMENDATIONS}

The following types of information and explanations should be provided to individuals by system or platform controllers when behavioral advertisements are served:

309. Mittelstadt, supra note 23, at 476-78.

310. Leading thinkers on collective privacy interests include BYGRAVE, supra note 263; Mittelstadt, supra note 23; Mantelero, Personal Data, supra note 245; Group PRIVACY: NEW Challenges of Data TECH., supra note 263.

311. Reilly, supra note 250.

312. Being labelled as a video gamer can cause the Chinese Social Credit Score to drop. See Kobie, supra note 252. 
1. Information that demonstrates that sensitive data and protected attributes have not been unlawfully used. Giving data subjects direct access (e.g., via Article 15 of the GDPR) to examine the data currently processed about them, as well as easy mechanisms to opt-out or withdraw consent for OBA, are similarly encouraged.

2. Information that provides individuals with a better understanding of what assumptions, predictions, or inferences are currently drawn about them. The current transparency efforts of tech companies, while an encouraging first step, are not sufficient. To better align explanations with the right to privacy and identity, users require better information about how they are "seen" by platforms and advertisers. ${ }^{313}$

In addition, the following modifications to public policy and business strategies should be made to improve the broader regulatory environment:

3. System or platform controllers should not use the argument that affinity profiling does not use, collect, or infer sensitive or protected attributes in order to avoid GDPR and non-discrimination law. Regulators and the judiciary should likewise reject any such argument. Even if affinity profiling is legally classified as involving sensitive information, companies should also not solely rely on consent to justify such processing. Companies should acknowledge that consent, as proposed in GDPR, is not always a reliable method to gauge user interests and preferences because most users do not read, and often do not understand, the terms and conditions of digital services. Companies should consider how to adopt ethical data analytics (e.g., a right to reasonable inferences for users (see Section A of this Article)), ${ }^{314}$ sharing practices, and business relationships ${ }^{315}$ (e.g.,

313. On the need for governance of inferential analytics, see Wachter \& Mittelstadt, supra note 39 , at 499 .

314. Id.

315. Sandra Wachter, The GDPR and the Internet of Things: A Three-Step Transparency Model, 10 L., INNOVATION \& TECH. 266, 278, 283-84, 292 (2018). 
fiduciary duties ${ }^{316}$ or duty of care ${ }^{317}$ ), and make information regarding these practices publicly available.

4. European regulators and policymakers should work to close relevant loopholes in current E.U. non-discrimination law. As shown in this Article, non-discrimination law is not comprehensive. However, it is clear that differential treatment and results, for example, based on religion or belief, disability, age, sexual orientation, ethnicity, and gender, should be avoided. Further, regulators, scholars, civil society organizations, policymakers, and industries should create guidelines for ethical business relations with partner companies to avoid unethical, stigmatizing and offensive advertisements. A public commitment to protect diversity (e.g., refraining from the use of certain sensitive data groups) in a holistic way is encouraged.

5. System controllers should undertake systematic and periodical bias testing to avoid unintentional discrimination. Bias testing is necessary to ensure that ad targeting systems are fair. As affinity profiling is based on the interests of user groups, it may be difficult to see that certain interests correlate with protected attributes. For example, postcodes can be strong proxies for religious belief or ethnicity. Therefore, internal structures that audit and test for bias need to be implemented. Collecting a list of known proxies and approaches to either avoid the usage of or to mitigate the risks associated with them could be made public. $^{318}$ Post codes ${ }^{319}$ and redlining ${ }^{320}$ regulations are a good example.

6. System controllers, regulators, and funding agencies should provide support for independent research or "white hat hacking" to determine

316. TAP Staff Blogger, Jonathan Zittrain and Jack Balkin Propose Information Fiduciaries to Protect Individual Privacy Rights, TECH. ACAD. POL'Y, https://www.techpolicy.com/Blog /September-2018/Jonathan-Zittrain-and-Jack-Balkin-Propose-Informat.aspx (last visited Feb. 2, 2019) [https://perma.cc/6AH6-EVG6]; see generally Jack M. Balkin, Information Fiduciaries and the First Amendment, 49 U.C. DAvis L. REV. 1183 (2015).

317. Lorna Woods \& William Perrin, An Updated Proposal by Professor Lorna Woods and William Perrin, CARNEGIEUK TRUST, https://www.carnegieuktrust.org.uk/blog/internet -harm-reduction-a-proposal/ (last visited May 11, 2019).

318. Similarly, Dalenberg proposes blacklists. See Dalenberg, supra note 174, at 625.

319. Wachter \& Mittelstadt, supra note 39, at 587.

320. On the history of redlining, see generally Willy E. Rice, Race, Gender, Redlining, and the Discriminatory Access to Loans, Credit, and Insurance: An Historical and Empirical Analysis of Consumers Who Sued Lenders and Insurers in Federal and State Courts, 1950-1995, 33 SAN DiEGO L. REV. 583 (1996). 
when, how, and to what extent certain groups are affected by affinity profiling. Due to the lack of algorithmic transparency, prima facie discrimination might be hard to prove. The claimant needs to show that they suffered a particular disadvantage and must demonstrate that a protected group is treated significantly worse (in comparison to others in a similar situation) for the burden of proof to shift. Therefore, more statistical evidence via independent research could help businesses to demonstrate that they are not discriminatory. Future policy discourse also needs to address whether the 80-90\% threshold ${ }^{321}$ for legally acceptable disparity is normatively acceptable.

7. Regulators, policymakers, and system controllers should acknowledge group-level privacy rights. Current profiling and inferential analytics are not sufficiently addressed in data protection and nondiscrimination law. The former lacks teeth because profiling can also occur without identifying an individual and sometimes even without using personal data, ${ }^{322}$ while the latter fails because the created groups do not map on to the protected groups in discrimination law. ${ }^{323}$ Therefore, a holistic privacy protection approach, as well as safeguards for people outside of these narrowly defined groups in nondiscrimination law (e.g., a right to reasonable inferences), ${ }^{324}$ should be pursued.

OBA and affinity profiling pose novel privacy, non-discrimination, and group privacy interests. Thankfully, it appears that E.U. non-discrimination law provides a powerful tool in discrimination by association to mitigate some of these risks. If the concept of discrimination by association is combined with robust transparency standards to explain how advertisements are served based on assumed interests and sensitive characteristics, the combination will greatly improve protection against pervasive online advertising practices.

321. See supra Section IV.B.2.

322. Wachter, supra note 21, at 7.

323. Mantelero, Personal Data, supra note 245, at 240.

324. Wachter \& Mittelstadt, supra note 39, at 500. 